\title{
Nanoscale Perspectives of Metal Degradation via In Situ Atom Probe Tomography
}

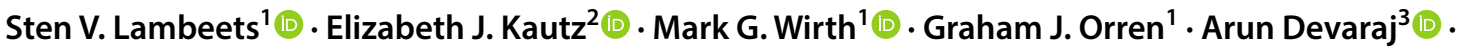 \\ Daniel E. Perea ${ }^{1}$ (1)
}

Published online: 21 September 2020

(c) The Author(s) 2020

\begin{abstract}
We report a unique in situ instrument development effort dedicated to studying gas/solid interactions relevant to heterogeneous catalysis and early stages of oxidation of materials via atom probe tomography and microscopy (APM). An in situ reactor cell, similar in concept to other reports, has been developed to expose nanoscale volumes of material to reactive gas environments, in which temperature, pressure, and gas chemistry are well controlled. We demonstrate that the combination of this reactor cell with APM techniques can aid in building a better mechanistic understanding of resultant composition and surface and subsurface structure changes accompanying gas/surface reactions in metal and metal alloy systems through a series of case studies: $\mathrm{O}_{2} / \mathrm{Rh}, \mathrm{O}_{2} / \mathrm{Co}$, and $\mathrm{O}_{2} /$ Zircaloy- 4 . In addition, the basis of a novel operando mode of analysis within an atom probe instrument is also reported. The work presented here supports the implementation of APM techniques dedicated to atomic to near-atomically resolved gas/surface interaction studies of materials broadly relevant to heterogeneous catalysis and oxidation.
\end{abstract}

Keywords Atom probe tomography $\cdot$ Atom probe microscopy $\cdot$ Oxidation $\cdot$ In situ $\cdot$ Operando $\cdot$ Cobalt $\cdot$ Rhodium $\cdot$ Zircaloy-4

\section{Introduction}

The physics governing chemical reactions at surfaces and interfaces, involved in both heterogeneous catalysis and oxidation processes, share fundamental synergistic interactions between reactant gases and specific surface structures [1]. Additionally, gas phase reactions on surfaces have

Electronic supplementary material The online version of this article (https://doi.org/10.1007/s11244-020-01367-z) contains supplementary material, which is available to authorized users.

Sten V. Lambeets

sten.lambeets@pnnl.gov

$\checkmark$ Daniel E. Perea

daniel.perea@pnnl.gov

1 Environmental Molecular Sciences Laboratory, Earth and Biological Sciences Directorate, Pacific Northwest National Laboratory, Richland, WA 99352, USA

2 National Security Directorate, Pacific Northwest National Laboratory, Richland, WA 99352, USA

3 Physical and Computational Sciences Directorate, Pacific Northwest National Laboratory, Richland, WA 99352, USA significant socioeconomic impact worldwide; heterogeneous catalysis directly impacts the productivity of all major chemical processes, whereas oxidation has serious implications for the safety and economic viability of national and private infrastructure. Importantly, scientific research into these phenomena are heavily pursued. However, a fundamental mechanistic understanding of gas-surface reactions leading to the development of oxide scale on metal substrates relevant to catalysis and oxidation remains inadequate, highlighting the need for the development and application of novel analytical techniques that can probe such reactions at relevant spatial and temporal scales.

As technology advances, surface science techniques are continuously evolving to help bridge knowledge gaps between fundamental research and real-world applications $[2,3]$ that can lead to a better understanding of gas/surface reactions in industrially relevant conditions. The development and application of in situ and operando analytical techniques are helping to address these gaps [3, 4] and recently, such approaches are being developed for atom probe microscopy (APM) using a combination of commercially available and custom built instrumentation $[5,6]$. 
The analytical techniques of 1-dimensional atom probe (1DAP), field ion microscopy (FIM) and field emission microscopy (FEM) are historically designated as field emission techniques (FET) [5,7-17]. With atom probe tomography (APT), these techniques are known collectively as atom probe microscopy (APM) $[18,19]$. The general experimental setup of APM techniques relies on a needle shaped specimen on a temperature-controlled stage with the surface pointing towards a detector within a high to ultra-high vacuum (UHV) environment. An electric field is either used to ionize individual gas atoms introduced to the analytical chamber (FIM), emit electrons directly from the surface (FEM), or trigger the field evaporation of surface atoms as positively charged ions (1DAP and APT). In the case of 1DAP, a timeof-flight detector or Wien filter can provide the chemical identification of detected ionic species [13, 20-24], while for APT, a position sensitive detector can provide tomographic composition mapping. Importantly, in the presence of reactive gases, FET analyses can be used to directly study surface reaction dynamics in situ to simultaneously reveal crystallographic information and material heterogeneity with sub-nanometer spatial resolution.

The difference in definition between the terms "in situ" and "operando" are still subject to semantical harmonization which varies by specific fields of study. Both terms refer to the analytical characterization of a material under an applied stimulus. However, within the field of heterogeneous catalysis, the term "in situ" refers to the analytical characterization of the system under reaction conditions or conditions relevant to reaction conditions, while "operando" describes the characterization under working or operating conditions [25]. Thus an in situ experiment can refer to experiments where the physiochemical characterization occurs subsequent to reaction conditions, often in a separate reactor chamber or cell, while an operando experiment is conducted in a way where the characterization occurs simultaneously under working conditions within the same chamber or tool. For the purpose of describing our work here, we consider controlled gas-phase exposure experiments using an annex reactor chamber connected to an atom probe tomography instrument and the pre- and post-characterization of which, as in situ. Alternatively, we use the term operando to designate an experimental approach in which the gas-phase exposure experiment and simultaneous characterization to occur within the analytical chamber of an atom probe tomography instrument; we define this explicitly as operando atom probe tomography.

The application of FET techniques in the field of surface science can reveal valuable insight into chemical reaction dynamics on nanoscale metal surfaces $[12,26$, 27], non-linear dynamics such as the oscillatory water formation [28], and even be used to track the path of activated oxygen atoms from their surface formation to their subsurface penetration [29]. During these studies, the specimen surfaces were directly imaged by FIM and FEM while exposed to reactive gases, allowing the observation of reaction dynamics in real time over a structurally complex hemispherical specimen surface. Although FET techniques continue to make important contributions to surface science, they also have their limitations. While FIM and FEM are capable of mapping the crystallographic structure of surfaces with atomic to nanoscale resolution, they generally cannot directly provide the chemical identity of individual species making up the surface composition or the composition of products formed during a chemical reaction. This limitation led Kruse et al. to adapt 1DAP to directly map surface dynamics as well as identify the chemical identity of subsequent surface products. The principle of such an approach, described elsewhere $[21,30]$, allowed for example, the study of NO adsorption dynamics on $\mathrm{Rh}$ restricted to a specific $\mathrm{Rh}(001)$ area of 150 atomics sites revealing stepped $\mathrm{Rh}(001)$ surface as more active in $\mathrm{N}-\mathrm{O}$ bond breaking than any other $\mathrm{Pt}$ surface structure. Additionally, Kruse et al. continues to pioneer research into the importance of E-fields involved in surface reactions and championing APM techniques as uniquely suited to study such phenomena [31].

The long history of Kruse et al. to adapt FET techniques to directly map chemical reaction dynamics on metal and metal alloy surfaces has laid the foundation for the further integration of in situ studies with APT [5, 6]. The analytical technique of APT is fundamentally related to field emission techniques, however, it is able to provide 3D atom-by-atom composition maps with subnanometer spatial resolution and part-per-million mass sensitivity. A significant advantage of the APT technique is the ability to analyze the 3D composition across buried interfaces or microstructural features, such as oxide/metal interfaces, as well as solute segregation to grain boundaries and dislocations. Thus, the combination of these APT and FET techniques, deemed APM, can provide a powerful means to resolve reaction dynamics and lead to fundamental mechanistic insight. For example, in collaboration with Kruse et al. our group at PNNL reported on the correlative combination of APM to study the mechanism of subsurface oxygen formation observed on $\mathrm{Rh}$ while exposed to either $\mathrm{O}_{2}, \mathrm{~N}_{2} \mathrm{O}$ or $\mathrm{CO}_{2}[5,29]$. This prior work reports efforts to unlock the promising use of APM techniques for surface-gas interaction studies and presents the most recent technical development performed in this direction.

In the original work presented here, we detail the design and operating principles of an in situ reactor directly attached to a Local Electrode Atom Probe (LEAP) instrument for studying material structure and composition changes via correlative FEM and APT. Results obtained using this capability are reported for a variety of material systems, including cobalt (Co), rhodium ( $\mathrm{Rh})$, and a 
zirconium $(\mathrm{Zr})$ alloy. All of these materials were exposed to pure $\mathrm{O}_{2}$ in situ. In addition to the in situ methodology and application to industrially relevant systems, the development of a unique operando mode of APT analysis within a LEAP instrument is also presented.

\section{Experimental Methods}

\subsection{Field Ion Microscopy (FIM)}

FIM imaging is an analytical imaging technique used to produce 2D maps of individual atom positions from a cryogenically-cooled specimen surface, revealing crystallographic structure with atomic resolution. The images produced by FIM result from the field ionization of imaging gas atoms, usually $\mathrm{Ne}$, over individual surface atoms under positive electrical bias [18, 32]. The creation of the intense E-field necessary to ionize $\mathrm{Ne}(35 \mathrm{~V} / \mathrm{nm})$ requires the specimen shape as a sharp needle with a few tens of nanometers radius curvature at the apex. The positively charged imaging gas ions are then point projected towards a detector screen usually made of a microchannel plate and a fluorescent screen. The resulting FIM image corresponds to a stereographic projection of the apex and allows the identification of the crystal orientations along with the exposed surface facets with atomic resolution $(0.2 \mathrm{~nm}$ lateral). In this work, the FIM images were obtained with a LEAP 4000X-HR Local Electrode Atom Probe APT system by CAMECA Instruments.

\subsection{Atom Probe Tomography (APT)}

Similar to FIM, the analytical imaging technique of APT relies on the thermally assisted field evaporation of positively charged ions from a needle shaped specimen within a high E-field. However, in the case of APT, individual surface atoms are ionized, as opposed to imaging gas atoms, thus making APT a destructive technique. Field evaporation is controllably initiated by applying either short voltage pulses or assisted with a laser beam, in the presence of a steady E-field. The atoms of a material can be extracted one by one as positively charged ions and projected onto a position sensitive detector, while the chemical identification of the detected ions is determined via time-of-flight mass spectrometry (ToF MS). Using the 3D position information and the ToF chemical identification, a 3D chemical map of the sample can be formed. A full description of this technique as well as references to the $3 \mathrm{D}$ data reconstruction details are provided by Gault et al. [18]. A LEAP 4000XHR Local Electrode Atom Probe APT system by CAMECA Instruments is used in the present study, with an approximate detector efficiency of $36 \%$. A pulsed $355 \mathrm{~nm}$ UV laser was used to induce thermally assisted field evaporation of specimens held at a stage temperature of $44 \mathrm{~K}$. Laser energy (100 pJ for Rh and Co; and $200 \mathrm{pJ}$ for Zircaloy-4) and pulse repetition rates $(100-125 \mathrm{kHz})$ varied based on material analyzed. Tomographic data reconstruction and analysis were performed using CAMECA's Integrated Visualization \& Analysis Software (IVAS) version 3.6.14.

\subsection{Sample Preparation}

All FIM and APT samples must be shaped as very sharp needles, which can be accomplished using different methods. Rh sample were prepared by electrochemical etching (EE) of a high purity Rh wire $(99.8 \%, \varnothing \sim 0.127 \mathrm{~mm})$ in a molten mixture of $\mathrm{NaCl}$ and $\mathrm{NaNO}_{3}(1: 4 \mathrm{w} / \mathrm{w})$ at $\sim 520{ }^{\circ} \mathrm{C}$, with a potential of $2 \mathrm{~V}_{\mathrm{DC}}$. Co samples were prepared by $\mathrm{EE}$ of high purity Co wire $(99.99+\%, \varnothing \sim 0.1 \mathrm{~mm})$ in droplets of two different solutions: (1) $25 \%$ perchloric acid (70\%) in glacial acetic acid and (2) $2 \%$ perchloric acid in 2-butoxyethanol [32]. Appropriated sample apex sharpness is confirmed using an optical microscope. Samples of Zircaloy-4 for in situ APT analysis were made from sectioned alloys mounted and prepared per procedures detailed in prior work [33]. APT sample preparation was performed using a FEI Quanta dual beam focused ion beam-scanning electron microscope (FIB-SEM). First, protective Pt capping layer was deposited on the alloy surface to protect the material from $\mathrm{Ga}$ ion damage during FIB milling. A cantilever was extracted from the base alloy, pieces of which were mounted onto a Si micropost array and shaped into needle-shaped specimens for APT analysis. Details regarding FIB-based APT needle preparation are provided elsewhere [34, 35].

\section{In-Situ Reactor}

\subsection{Design and Operation}

The ability to experimentally control the ambient reaction conditions relevant to an atomic to nanoscale understanding of oxidation or catalysis on a metal or metal alloy surface is enabled by a reactor connected to an atom probe instrument. The design, fabrication, and demonstration of a gasphase reactor attached to an atom probe has been previously reported by Bagot and Visart de Bocarmé et al., and was demonstrated to explore reactive gas interactions on bimetallic metal systems: $\mathrm{H}_{2} / \mathrm{Pd}[36], \mathrm{O}_{2} / \mathrm{Mg}$ alloy [36, 37], $\mathrm{NO} /$ $\mathrm{PtRh}$ [38], $\mathrm{O}_{2} / \mathrm{PtRh}[6]$ and $\mathrm{O}_{2} / \mathrm{AuAg}$ [39]. They reported local chemical segregation within the bulk and on material surfaces such as Ag- and Rh-enriched surface layers induced by $\mathrm{O}_{2}$ exposure of AuAg and PtRh respectively, or Rh depletion caused by $\mathrm{NO}$ adsorption on PtRh.

At PNNL, significant effort has been dedicated to developing a suite of hardware and experimental protocols for the 
preparation and handling of environmentally sensitive materials centered around a unique environmental transfer hub (ETH) chamber [40]. The ETH is a vacuum chamber which hosts a specimen puck carousel with rotational and vertical translation allowing the storage and transfer of specimens to the LEAP under UHV conditions. Importantly, the central hub chamber design also allows the connection of ancillary chambers, such as an Environmental Chemical Reactor (ECR) for controlled gas-phase surface reaction studies and UHV specimen transfer to the LEAP for APT analysis. The ETH and ECR attached to the LEAP APT system is shown in Fig. 1a.

The ECR, designed in collaboration with OmniVac (Germany) is defined as a dedicated reactor chamber connected to the ETH enabling the gas-phase exposure of specimens under controlled ambient conditions (i.e. temperature, pressure, time). Within the main ECR chamber is a secondary cylindrical volume making up a heated reactor cell where the specimen is held and gas lines feed the flow of reactant gases (Fig. 1b). The temperature is measured directly on the specimen stage near the specimen position with a type K thermocouple. The design of the ECR allows the specimen stage to be heated to $500{ }^{\circ} \mathrm{C}$ and gas pressures of up to $1 \mathrm{~atm}$. The specimen stage is attached to a vertical transfer rod assembly that moves between positions for controlled experimental reactions and specimen transfer to/from the ECR and atom probe under UHV. To eliminate the need to move specimens between various specimen pucks we designed the specimen stage to be compatible with the specific pucks used for APT analysis in a CAMECA LEAP instrument.

The controlled introduction of reactant gases into the ECR occurs through a gas mixing network consisting of a central 1 inch diameter gas mixing tube manifold connected to nine separate gas lines, including $\mathrm{H}_{2}(>99.9 \%)$, $\mathrm{O}_{2}(99.993 \%),{ }^{18} \mathrm{O}_{2}$ (99\%), $\mathrm{CO}_{2}$ (>99.9\%), CO (10\% in Ar), $\mathrm{N}_{2}(>99.9 \%)$ and three variable lines labeled as $\mathrm{X}, \mathrm{Y}$ and $Z$. The gas mixing manifold design allows the exposure of specimens to either pure gases or variable gas mixes. The gas introduction network allows gas mixture introduction into the reactor at three working pressure ranges: (1) for a pressure between $10^{-7}$ and $10^{-3} \mathrm{mbar}$, the gas is introduced into the chamber through a variable leak valve (Fig. 1c, red path), connected to a low-pressure reservoir. The pressure in the reservoir is maintained constant with a pressure controller (PC2). Within this range of pressure, the reactor can be used in static (batch) or continuous reactant gas flow mode. In batch mode, the central reactor cell is closed and the whole ECR chamber is isolated and the reactor cell is filled with reactant gases to the desired pressure. In continuous mode, the leak valves are manipulated to allow a continuous gas flow at a desired pressure while continuously being evacuated by the pumping system. This latter mode of gas introduction is only possible at a range of pressures between $10^{-7}$ and $10^{-3}$ mbar. (2) For pressures between $10^{-3}$ and $100 \mathrm{mbar}$, the gas is introduced into the chamber through a needle valve (Fig. 1c, blue path). (3) For pressures of $100 \mathrm{mbar}$ to $1000 \mathrm{mbar}$ (atmospheric pressure), gases are introduced into the chamber through a quarter-turn valve (Fig. 1c, green path).

As a general workflow for gas exposure experiments, the specimen stage temperature is set and allowed to reach a stable temperature prior to the introduction of the specimen into the reactor cell. In parallel, prior to any experiment, the specimen is cleaned within the LEAP of any surface contaminants that remain from EE or FIB-based preparation by field evaporation of a few 10's of nanometers. The sample is considered as clean when contaminants, resulting from the fabrication process, are not detected anymore. Typical contaminations detected vary between the different fabrication processes: chlorine and derivates from EE and gallium from FIB.

\subsection{In Situ APT Studies of Pure Metal Oxidation}

\subsubsection{Rhodium Oxidation}

Rhodium, as every other Platinum group metal, is highly appreciated for its catalytic properties, its oxidation resistance and finds an important role within the catalytic exhaust systems equipped on every modern gasoline or diesel motor vehicle. The role of $\mathrm{Rh}$, is the neutralization of toxic $\mathrm{NO}_{\mathrm{x}}$ gases expelled by the engine, into harmless water and $\mathrm{N}_{2}$. Alternatively, $\mathrm{Rh}$ also has the capability to dissociate $\mathrm{CO}_{2}$ and participate in $\mathrm{CO}_{2}$ revalorization by catalytic conversion. However, the apparent oxidation resistance of $\mathrm{Rh}$ and $\mathrm{Pt}$ results from their ability to bond with oxygen atoms to form a thin protective oxidized layer. Subsequently, the catalytic activity of these metals evolves with their surface oxidation. In our previous work, we used the combination of FIM/FEM and APT to establish 3D chemical mapping analysis of the $\mathrm{O}$ atoms over and under the Rh surface [5, 29].

Before the in situ oxygen treatment, the Rh surface is cleaned by field evaporation in the LEAP analytical chamber and a FIM image is taken with the use of Ne as imaging gas. The FIM image depicted in Fig. 2a displays a Rh single crystal in a 001-orientation due to its central (001) facet. Following the LEAP-based cleaning process, the cleaned $\mathrm{Rh}$ surface presents a small amount of native contaminants such as water, carbon monoxide, carbon dioxide and $\mathrm{Rh}$ oxides (Fig. 2b), but the sum of these contaminants $(\mathrm{C}, \mathrm{H}$ and $\mathrm{O}$ atoms) represent less than $0.7 \%$ of the total ions detected within the volume analyzed of $25 \mathrm{~nm}$ depth corresponding to 66 atomic layers.

After a $30 \mathrm{~min} \mathrm{O}_{2}$ exposure $\left(\mathrm{P}\left(\mathrm{O}_{2}\right)=1.0 \times 10^{-3}\right.$ mbar $)$ at $750 \mathrm{~K}$, a significant amount of $\mathrm{RhO}_{\mathrm{x}}^{\mathrm{n}+}(\mathrm{x}=1,2 ; \mathrm{n}=1$, 2) species are detected dominated by $\mathrm{RhO}^{+}, \mathrm{RhO}_{2}{ }^{+}$, 

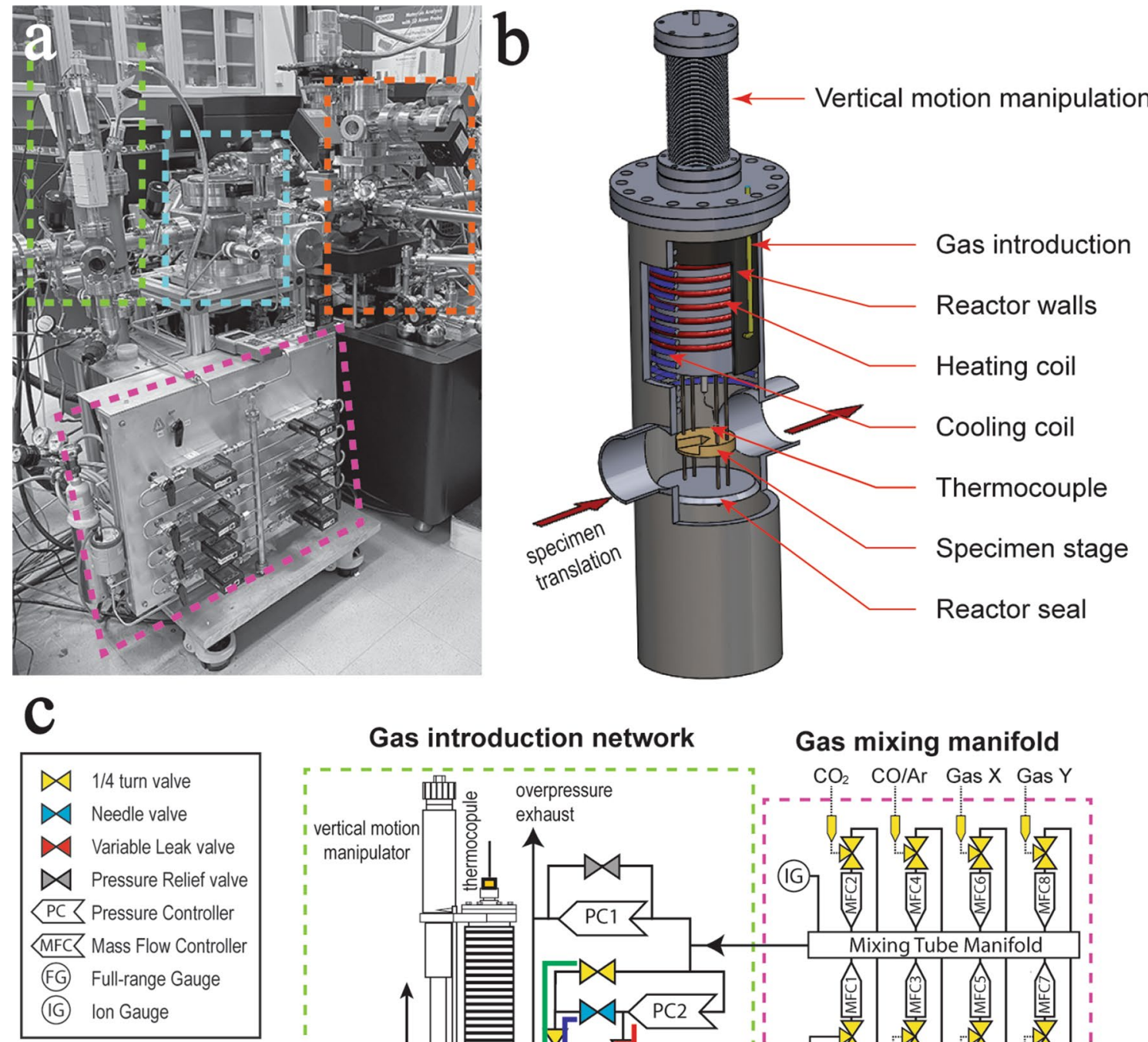

\section{Gas introduction network}

Gas mixing manifold

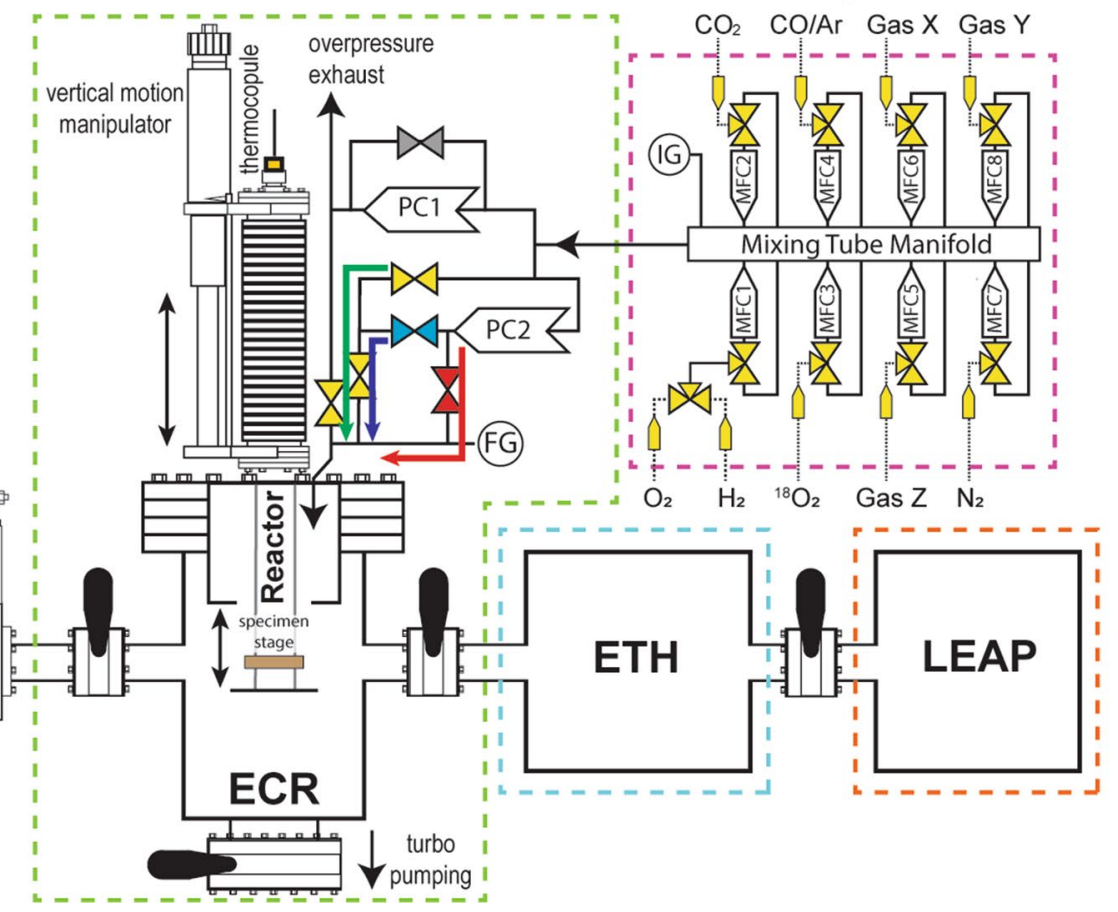

Fig. 1 Design of a custom gas phase reactor for in situ APT studies. a Photograph of the reactor and the gas introduction network (green) connected to the gas mixing manifold (red) and the ETH (blue), con-

$\mathrm{RhO}^{2+}$ and $\mathrm{RhO}_{2}{ }^{2+}$ at $119 \mathrm{Da}, 135 \mathrm{Da}, 59.5 \mathrm{Da}$ and $67.5 \mathrm{Da}$ respectively (Fig. 2d). The $\mathrm{RhO}_{\mathrm{x}}^{\mathrm{n}+}$ species represent up to $20 \%$ of the ions detected in the first $2 \mathrm{~nm}$ near the surface. The 2D composition map of $\mathrm{RhO}_{\mathrm{x}}^{\mathrm{n}+}$ and $\mathrm{O}^{+}$, shown as a nected to the LEAP system (orange). b 3D inside view of the reactor cell. c Schematic description of the reactor system and its gas introduction networks

heat map (Fig. 2c) shows that the density of oxygen atoms and $\mathrm{Rh}$ oxides species are concentrated over the specific crystal orientations (001), $\{113\}$ and (101). Notably, the $\mathrm{O}$ atoms represent up to $40 \%$ of the atoms detected in 


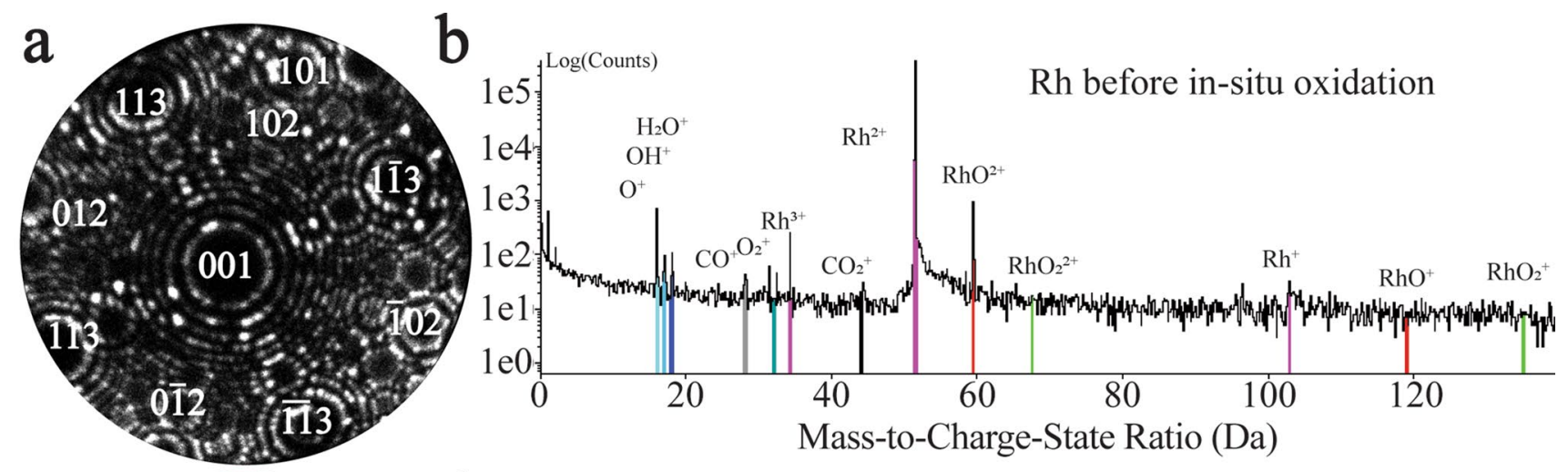

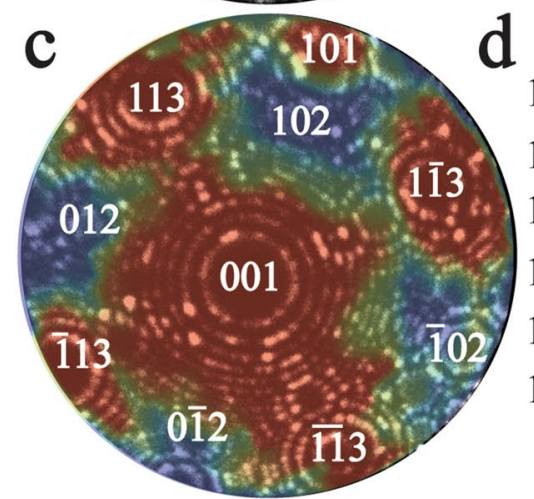

$\begin{array}{lllllll}0.0 & 0.1 & 0.2 & 0.3 & 0.4 & 0.5 & 0.6\end{array}$ $\left(\mathrm{RhO}, \mathrm{RhO}_{2}, \mathrm{O}\right)\left(\# / \mathrm{nm}^{3}\right)$

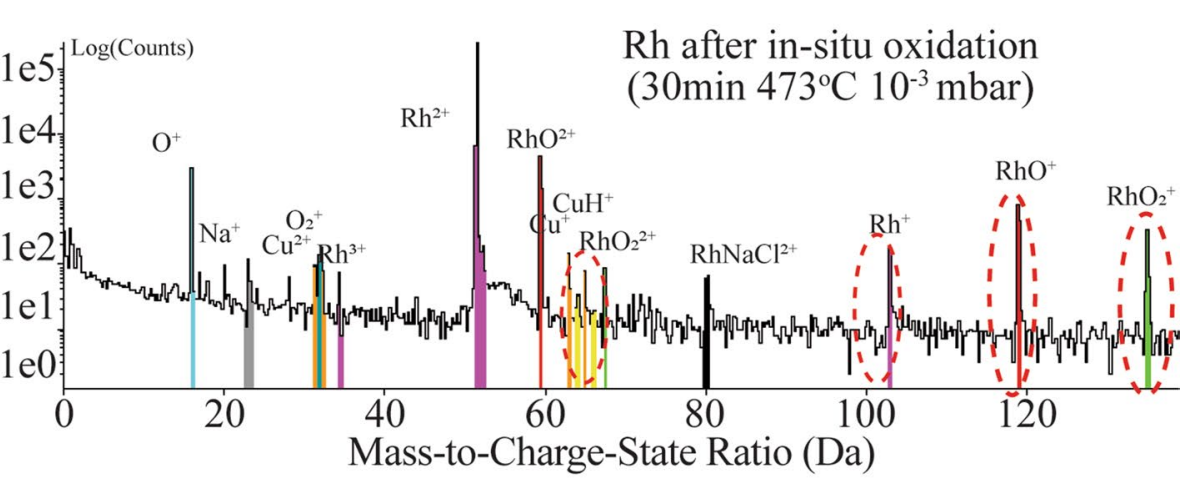

Fig. 2 Oxidation of Rh. a FIM image of (001) oriented Rh. Conditions of acquisition: $40.0 \mathrm{~K}, 3700 \mathrm{~V}, \mathrm{P}(\mathrm{Ne})=2.2 \times 10^{-6}$ mbar. b Mass spectra of the Rh sample after cleaning the surface by field evapo-

the first nanometers of the $\{113\}$ regions. Similar results have been obtained in our previous work on (001)-oriented $\mathrm{Rh}$ samples and APT on (111)-oriented Rh samples [5] where FIM/FEM experiments suggested that $\mathrm{O}_{2}$ dissociative adsorption occurs over $\{012\}$, followed by the $\mathrm{O}$ (ads) spillover to $\{113\}$ vicinal facets resulting in the penetration of subsurface oxygen $\mathrm{O}$ (sub). The current results presented in Fig. 2 show the highest oxygen concentrations over the specific crystal orientations of (001) and $\{113\}$ through which the oxygen penetration is preferential and serve to confirm our previous conclusion [5] which is in line with other studies in literature [41, 42]. A FIM image can be taken after exposure to $\mathrm{O}_{2}$, but the obtention of a clean FIM image requires the evaporation of the gas molecules adsorbed over the surface, a process that can result in the evaporation of the first atomic layers of the surface and the subsequent compromising of the APT analysis of the intentional oxide. During our investigation, we didn't observe noticeable surface reconstruction or crystallographic orientation modification of the sample after its exposition to $\mathrm{O}_{2}$ (not shown). We can note the presence of remaining contaminants such as $\mathrm{Cu}, \mathrm{Na}$ and $\mathrm{NaCl}$. These ration. c $2 \mathrm{D}$ projection of $\mathrm{RhO}_{\mathrm{x}}^{\mathrm{n}+}$ composition density after oxygen exposure. d Mass spectra of a Rh sample after oxygen exposure

contaminants are diffusing from the sides of the needle during the oxidation treatment at $750 \mathrm{~K}$. The presence of $\mathrm{Na}$ and $\mathrm{NaCl}$ results of the electrochemical etching process using molten salts, while the $\mathrm{Cu}$ contamination results from the diffusion of $\mathrm{Cu}$ from the $\mathrm{Cu}$ sleeves in which the $\mathrm{Rh}$ needle is crimped.

The combination of FIM/FEM and an in situ reactor with APT allowed us to provide a highly accurate map of the path taken by oxygen atoms. Critical to the ability to identify the different crystal orientations of the surface, and subsequently reconstruct the dynamics of $\mathrm{Rh}$ oxidation, was the ability to fabricate $\mathrm{Rh}$ wire into needle shaped specimens with a single crystal terminus. From $\mathrm{O}(\mathrm{ads})$ formation following dissociative adsorption over $\{012\}$ to their penetration into the bulk through $\{113\},\{111\}$ and $\{001\}$ vicinal facets and $\mathrm{O}(\mathrm{sub})$ formation, it is the unprecedent local atomic to near atomic resolution composition mapping which makes APM a highly suited for near-surface/gas interaction studies. The results presented here were enabled by the fabrication of specimens as single crystal sharp needles, which is can be a great challenge to overcome. 


\subsubsection{Cobalt Oxidation}

The use of Co-based catalysts in Fischer-Tropsch synthesis and $\mathrm{CO}_{2}$ hydrogenation is well establish especially in gas-to-liquid (GTL) industrial chemical production plants, however Co suffers from rapid ageing decreasing its catalytic activity leading to a decay in the global activity within only few months [43]. Metallic Co presents different crystalline forms, $\alpha-\mathrm{Co}$ (hcp) and $\beta$-Co (fcc), with different surface and chemical properties; the fcc form is more stable, while the hcp form is more active in FT synthesis [44]. Additionally, the ageing process leads to structural modifications of the Co surface during the ongoing reaction to $\mathrm{CoO}$ (fcc) and $\mathrm{Co}_{3} \mathrm{O}_{4}$ (spinel). The strong influence of particle size, shape and composition on reactive properties has been demonstrated for pure $\operatorname{Co}(0)$ metal $[45,46]$. Most recent investigations, some by Kruse et al. propose to tune Co catalytic properties by alloying with $\mathrm{Cu}$ and $\mathrm{Mn}$ metals or to prepare size-selective NPs on suitable supports [46-49]. However, changes to nanoparticle shape and formation of complex surface and subsurface compositional heterogeneity during exposure to oxygen is challenging to investigate and can be aided by APM studies. Within this context, we have chosen to investigate Co oxidation by following the same methodological pathway than Rh described in the previous section. Following FIM analysis of Co needle wire specimens prepared via EE, we will present the APT analytical results of native and controlled oxidation. We will present the first results as well as the challenges that are yet to overcome.

Contrary to Rh, Co exhibits various crystal structures that enhance polycrystallinity of the samples which presents practical challenges to APM based analyses. The first FIM analyses were reported by Nishikawa and Muller in 1967 [50] and already attempted to overcome the high polycrystallinity of Co. The polycrystallinity of Co is typically detected by the presence of linear surface defects (i.e. grain boundaries) that will affect the surface dynamics such as $\mathrm{O}$ penetration within the bulk, but also unfortunately, makes it very challenging for crystal orientation identification with the use of the stereographical projection approach.

As depicted on Fig. 3a, FIM imaging reveals a Co surface highly impact by surface defects (white arrows), resulting in the presence of multiple nanocrystals delineated with white dashed lines. One of the major challenges posed by the polycrystallinity, besides the difficulty to identify specific crystal orientation surface structure, is that the exposed surface structure may evolve during field evaporations between subsequent APT analysis of the same tip. As illustrated on Fig. 3b, Co APT imaging of a Co native surface oxide presents inhomogeneous penetration of the oxygen within the bulk. Within the first $5 \mathrm{~nm}$ below the surface, the most oxidized region exhibits a 1:1 ratio in the detected $\mathrm{Co}$ and $\mathrm{O}$ atoms, which is consistent with the stochiometric $\mathrm{CoO}$ oxide
(Fig. 3c). After field evaporation cleaning to remove native Co oxide from the surface, the sample is directly transferred to the reactor for oxygen exposure. After three successive oxygen exposure/APT analysis cycles at $300{ }^{\circ} \mathrm{C}$ for $10 \mathrm{~min}$, a FIM image was taken to reveal the evolution of the surface structure and oxide distribution as shown in Fig. 3d. Empirically, the surface appears smoother with fewer surface defects and only three disguisable crystallographic zones on the surface delineated with white dashed lines on the FIM image. At this state, the overall surface structure does not evolve anymore and is considered as stable for a further controlled $\mathrm{O}_{2}$ exposure. From this clean surface, the sample is exposed to oxygen $\left(\mathrm{P}\left(\mathrm{O}_{2}\right)=9.0 \times 10^{-5} \mathrm{mbar}\right)$ at $300{ }^{\circ} \mathrm{C}$ during $10 \mathrm{~min}$. The oxygen distribution displayed as a $2 \mathrm{D}$ concentration profile shows an enhancement that is highlighted over zone 1 and 3 (Fig. 3e-f). The concentration of penetrated oxygen varies from 30 to $20 \%$ along the first 5 $\mathrm{nm}$ of the Co surface (Fig. 3f). If the $\mathrm{CoO}^{\mathrm{n}+}$ (detected at 75 and $37.5 \mathrm{Da}$ ) distribution geographically follows the oxygen atom distribution, the $\mathrm{Co}_{2} \mathrm{O}^{\mathrm{n}+}$ (detected at $67 \mathrm{Da}$ ) is mainly detected along the surface defects delimiting the three separate nanocrystals (Fig. 3g-h). The respective $\mathrm{CoO}^{\mathrm{n}+}$ and $\mathrm{Co}_{2} \mathrm{O}^{\mathrm{n}+} 1 \mathrm{D}$ concentration profiles probed in regions $\mathrm{R} 1$, in the middle of zone 1, and R2, on a surface defect, show a significant $\mathrm{Co}_{2} \mathrm{O}^{\mathrm{n}+}$ enrichment in defect region $\mathrm{R} 2$ with a concentration varying between 15 and $5 \%$ in the first $5 \mathrm{~nm}$ depths, while this $\mathrm{Co}_{2} \mathrm{O}^{\mathrm{n}+}$ concentration never outreach $5 \%$ in R1 (Fig. 3i). Even if it is challenging to clearly identify the specific crystallographic structure, it is clear that the Co oxidation process is inhomogeneous and depends on these surface structures (Fig. 3f), with such surface defects offering potential binding sites for $\mathrm{O}_{2}$ molecules with variable dissociative adsorptions. An example of mass spectra of oxidized Co can be found in supplementary information.

Following a similar workflow, we proceeded with the successive oxidation of cleaned Co surface obtained from one different Co specimen at different temperatures between $200{ }^{\circ} \mathrm{C}$ and $350{ }^{\circ} \mathrm{C}$ to observe the progression of the oxidation front with APT after 5, 10, 15, 30 and 60 min of $\mathrm{O}_{2}$ exposure. For each reconstruction, the number of $\mathrm{O}$ atoms detected were counted and reported on Fig. 4a. The number of $\mathrm{O}$ atoms are counted by from the decomposed composition of every oxygen carrier species including: $\mathrm{O}^{\mathrm{n}+}, \mathrm{O}_{2}^{\mathrm{n}+}$, $\mathrm{CoO}_{\mathrm{x}}^{\mathrm{n}+}, \mathrm{HO}^{\mathrm{n}+}$ and $\mathrm{H}_{2} \mathrm{O}^{\mathrm{n}+}$. As expected, the strongest oxidation rates are found for temperatures higher than $300{ }^{\circ} \mathrm{C}$ with the surface oxidized layer fully converted to $\mathrm{CoO}$ after only $30 \mathrm{~min}$ at $350{ }^{\circ} \mathrm{C}$. The progression of the oxide front into the metal is depicted in Fig. $4 \mathrm{~b}$ which reports the Co and $\mathrm{O}$ atoms composition (\%) of the sample along the $\mathrm{z}$ axis from the surface. From these fronts it is possible to estimate the average speed of oxygen penetration within the bulk and reconstruct the path of oxygen atoms during the oxidation process. Considering 5 and $30 \mathrm{~min}$ oxygen 


\section{Native Co Oxidation}

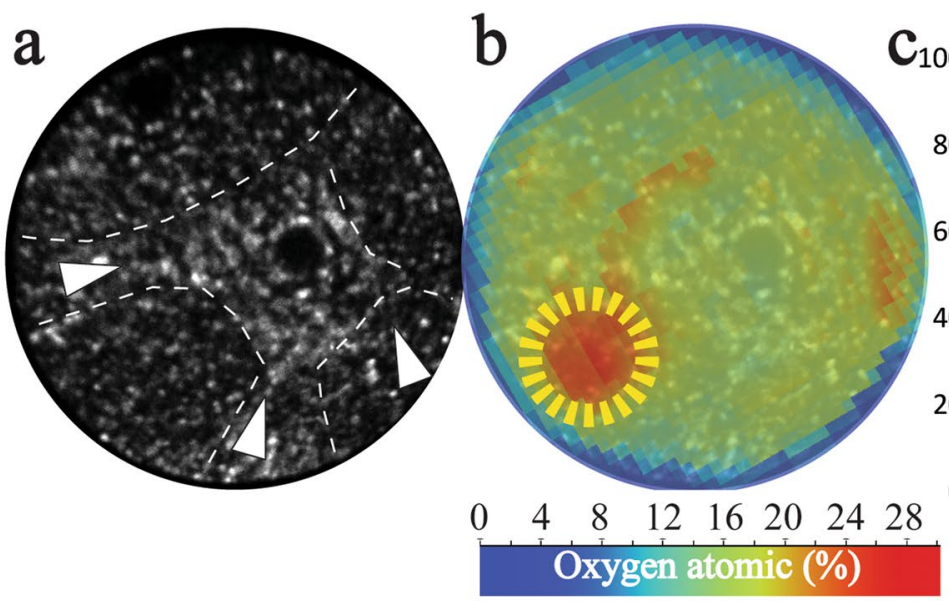

Concentration (at $\%$ )

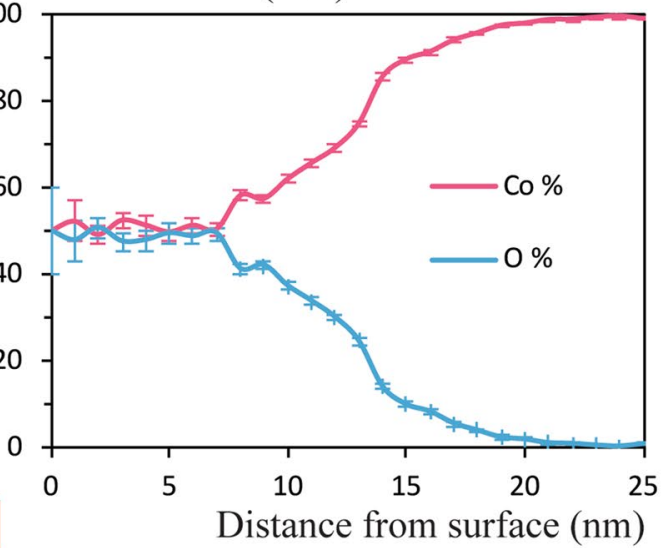

\section{Controlled Co Oxidation}
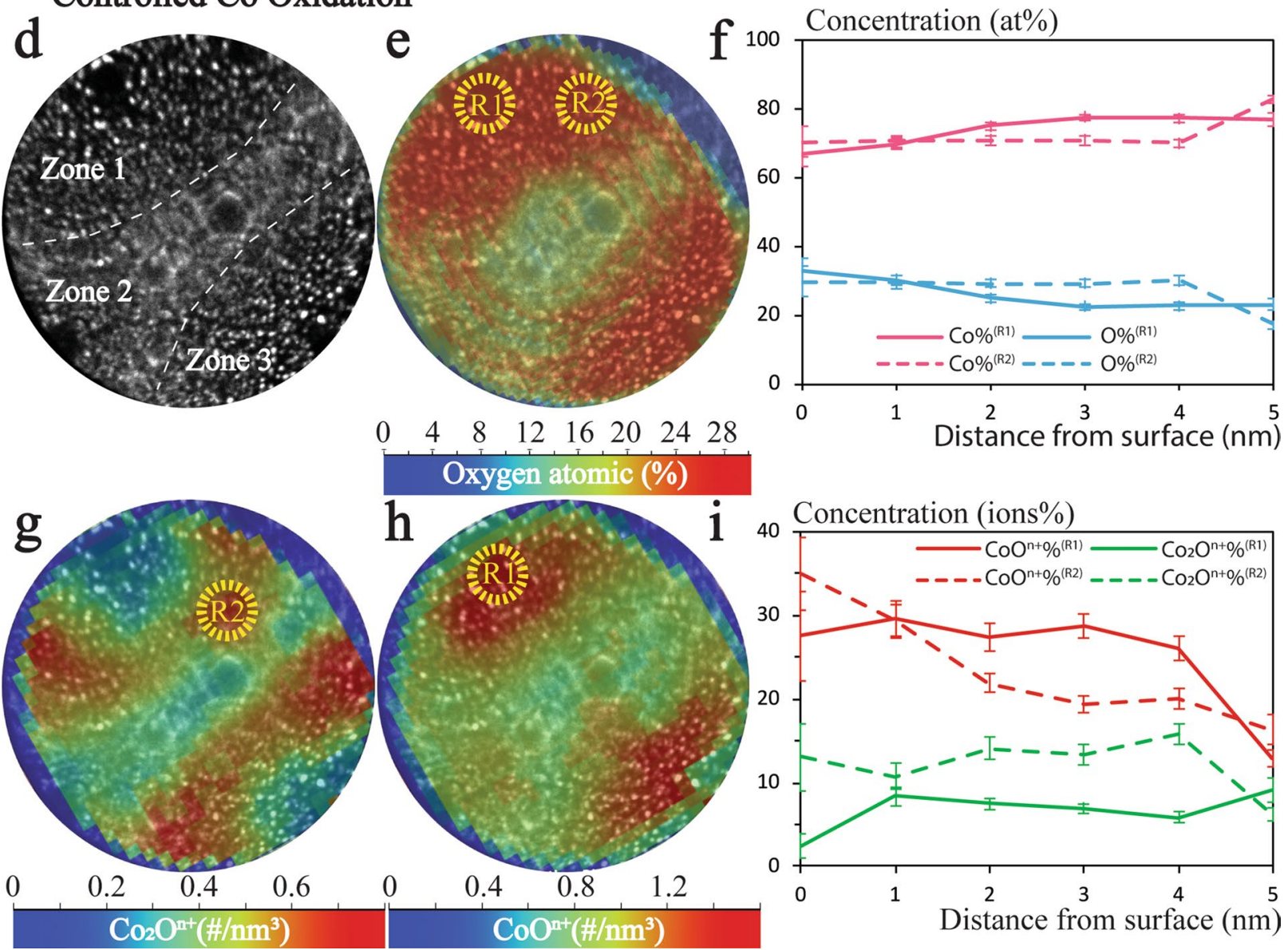

\section{Oxygen atomic (\%)}
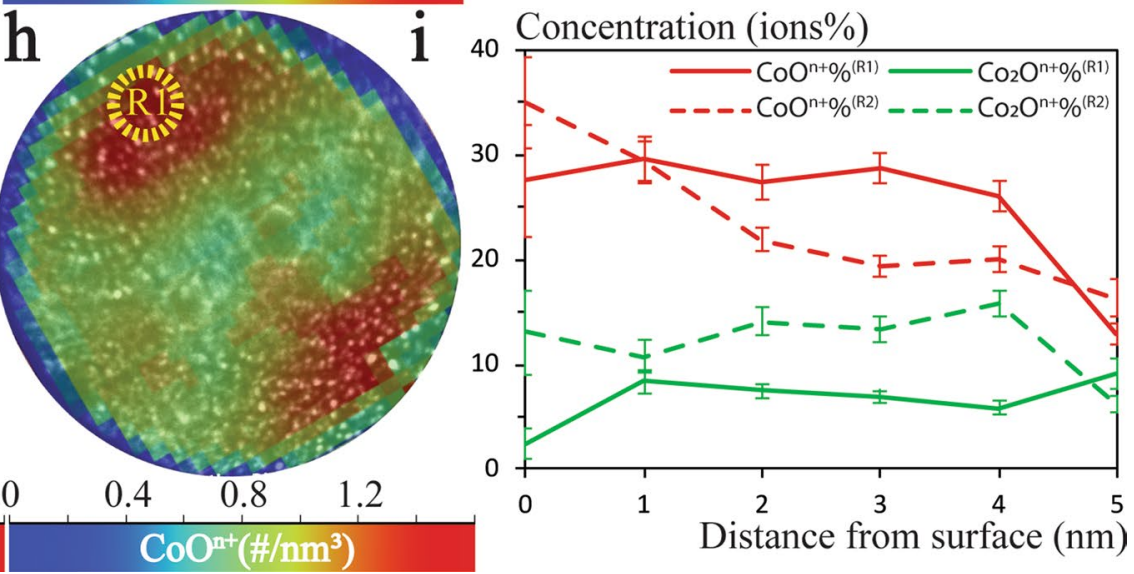

Fig. 3 Mapping oxide distribution over the surface and within the bulk. Concentration plots are measured within $1 \mathrm{~nm}$ bins width. a FIM image of a Co sample after the first cleaning process. (Conditions of acquisition: $28.6 \mathrm{~K}, 6800 \mathrm{~V}, \mathrm{P}(\mathrm{Ne})=9.7 \times 10^{-7}$ mbar). b $2 \mathrm{D}$ projection of $\mathrm{O}$ atoms concentration (at\%) of the Co APT reconstruction after field evaporation cleaning of the native oxide. c 1D concentration profile in $\mathrm{Co}$ and $\mathrm{O}$ atoms detected along the $\mathrm{z}$ axis of the region of interest depicted on (b) with a yellow circle. d FIM image of a Co sample after three separate field evaporation runs removing the oxide. (Conditions of acquisition: $20.0 \mathrm{~K}, 7600 \mathrm{~V}$,
$\mathrm{P}(\mathrm{Ne})=2.6 \times 10^{-7}$ mbar). e $2 \mathrm{D}$ projection of $\mathrm{O}$ atom concentration $(\%)$ of the Co reconstruction after oxygen exposure $(\mathrm{t}=10 \mathrm{~min}$, $\left.\mathrm{T}=573 \mathrm{~K} ; \mathrm{P}\left(\mathrm{O}_{2}\right)=9.0 \times 10^{-5} \mathrm{mbar}\right)$ and $\mathbf{f}$ the $1 \mathrm{D}$ concentration profile in $\mathrm{Co}$ and $\mathrm{O}$ atoms detected along the $\mathrm{Z}$ axis of the regions of interest $\mathrm{R} 1$ and $\mathrm{R} 2 . \mathrm{g} 2 \mathrm{D}$ projection of $\mathrm{Co}_{2} \mathrm{O}^{\mathrm{n}+}$ species density (\#/ $\mathrm{nm}^{3}$ ) and $\mathbf{h} 2 \mathrm{D}$ projection of $\mathrm{CoO}^{\mathrm{n}+}$ species density $\left(\# / \mathrm{nm}^{3}\right)$ of the Co reconstruction after oxygen exposure. $\mathbf{i}$ respective $1 \mathrm{D}$ concentration profiles in $\mathrm{Co}_{2} \mathrm{O}^{\mathrm{n}+}$ and $\mathrm{CoO}^{\mathrm{n}+}$ species detected along the $\mathrm{Z}$ axis of the regions of interest $\mathrm{R} 1$ and $\mathrm{R} 2$ 
exposures as "extremes" between the full transformation of $\mathrm{Co}$ into $\mathrm{CoO}$, the 10 and 15 min oxygen penetration front plots present two distinguishable sections, a first part with a relatively linear $\mathrm{O} \%$ decreasing and a second part with a concave curve shape. By calculating the first and second derivate of these curves, it becomes possible to find the inflection point between the two parts and we used these inflection points to measure the position of the front over time (i.e. distance). Since we know the time, we are able to calculate an estimated speed as distance/time. The front progression speed is estimated at $2.1 \mathrm{~nm} \cdot \mathrm{min}^{-1}$ between the 5 and $10 \mathrm{~min}$ fronts, and $4.2 \mathrm{~nm} \cdot \mathrm{min}^{-1}$ between the 10 and 15 min fronts. In first approximation we observe that the oxidation seems to accelerate over time until reaching a full $\mathrm{CoO}$ volume $(30 \mathrm{~min})$. We hypothesize that this acceleration probably reflects the fact that the oxygen atoms penetrate the Co needle isostatically from every direction. Note that here we are considering this penetration with only one dimension and thus is only a first approximation [37]. The next steps of this work will consist of improving the reconstruction scaling based on correlative TEM imaging of the needle shape taken before/after oxidation. Such geometrical information will guide APT reconstruction parameters as well as provide information about the precise surface exposed to $\mathrm{O}_{2}$ needed to build a model that consider the oxygen penetration from every direction. In the case of $\mathrm{Co}$, its polycrystallinity poses the problem that the surface exposed evolves as the specimen is evaporated. The consequence is directly observable in Fig. 4a where the number of $\mathrm{O}$ atoms detected at $300{ }^{\circ} \mathrm{C}$ after 15, 30 and $60 \mathrm{~min}$ are significantly lower than after $15 \mathrm{~min}$. Such evolution may be the result of a drastic change of the surface exposed at $10 \mathrm{~min}$ experiment and at $15 \mathrm{~min}$ and following.

The multiplication of these measurements at different temperature/pressure on different specimen and the experimental reconstructions of the oxygen front progression will be used to support theoretical efforts aimed at building a better understanding of these bulk diffusion mechanisms.

For APT, the major challenge to overcome is the samples fabrication and the stabilization of a single crystal. With a stable single crystal, we believe that this methodology has the unprecedent capability to experimentally reconstruct the full oxidation process of Co from the first surface/gas interactions to the subsurface and bulk diffusion mechanisms, and will lead to a better understanding of the mechanistic relationships existing between surface, subsurface and bulk during surface reactions. A direct application of this method can be reasonably considered in the case of "real" nanoparticles such as enriched Co nanoparticles, $\mathrm{Co} / \mathrm{MnO}_{\mathrm{x}}$ [47], and nanoalloys, $\mathrm{CoCu}$ [51]. Finally, it is important to notice that even if the oxygen exposure is performed in absence of electric field, the precise mechanism of field evaporation remains widely unknown and is still a matter of discussion within the APM community [52]. For the Co oxidation case, an additional investigation will be necessary to determine the influence of the electric field and the laser energy on the nature of the ions detected [53].

\subsection{In Situ APT Studies of Alloy Oxidation}

Beyond catalytic materials, the in situ APT approach is also valuable for studying early stages of alloy oxidation relevant to various applications, from nuclear energy to structural materials [37, 54]. Traditionally, alloy oxidation behavior is studied with longer-term experiments (on the order of several to tens to even hundreds of days) in which samples are exposed to the oxidative or corrosive environment of interest. During these experiments, samples are removed at different time steps and characterized using analytical techniques such as electron microscopy and APT to understand changes in structure-composition accompanying the oxidation or corrosion process. However, using this approach the time scales accessible are limited, making it challenging to monitor how the composition and crystallography changes across the evolving oxide/metal interface and in the oxide itself, especially in early stages of oxidation. Hence, we have adapted the in situ APT approach to help us better understand initial composition changes that occur across the oxide/metal interface during initial alloy oxidation up to time durations of $5 \mathrm{~min}$. Here, we summarize our findings on zirconium alloy (Zircaloy-4) oxidation, and discuss important sample preparation considerations for these experiments [33].

Zirconium ( $\mathrm{Zr}$ ) alloys are used in the nuclear industry as reactor fuel cladding and tritium absorbing materials, owing to their favorable combination of corrosion resistance, low neutron cross section, and mechanical properties [55-57]. In both of these applications, $\mathrm{Zr}$ alloys experience waterside corrosion, which can significantly impact structural integrity and limit component lifetime [58]. During waterside corrosion, both oxidation and hydrogen $(\mathrm{H})$ ingress occur, and are phenomena that have been studied extensively for a variety of $\mathrm{Zr}$ alloys [58]. However, the evolution of composition and structure across the oxide/metal interface is still an active area of research, due to its important role in corrosion kinetics [59]. Application of the in situ APT approach enables us to track composition changes during the very early stages of oxide film developent on an industrially relevant $\mathrm{Zr}$ alloy, Zircaloy-4, with composition $1.02 \pm 0.03 \mathrm{Sn}, 0.72 \pm 0.02$ $\mathrm{O}, 0.38 \pm 0.01 \mathrm{Fe}, 0.23 \pm 0.01 \mathrm{Cr}$ in at. \% with balance $\mathrm{Zr}$. Changes in $\mathrm{Zr}$ and $\mathrm{O}$ concentrations from before intentional oxidation (i.e. native air oxide) to after intentional oxidation for 1 and 5 min time steps at $300{ }^{\circ} \mathrm{C}$ and $10 \mathrm{mbar}_{2}$ were determined [33], with results after the longest oxidation time step ( $5 \mathrm{~min}$ ) summarized in Fig. 5. After just $5 \mathrm{~min}$, a mutilayered oxide film was developed, consisting of $\mathrm{ZrO}, \mathrm{ZrO}_{2-\mathrm{x}}$, 

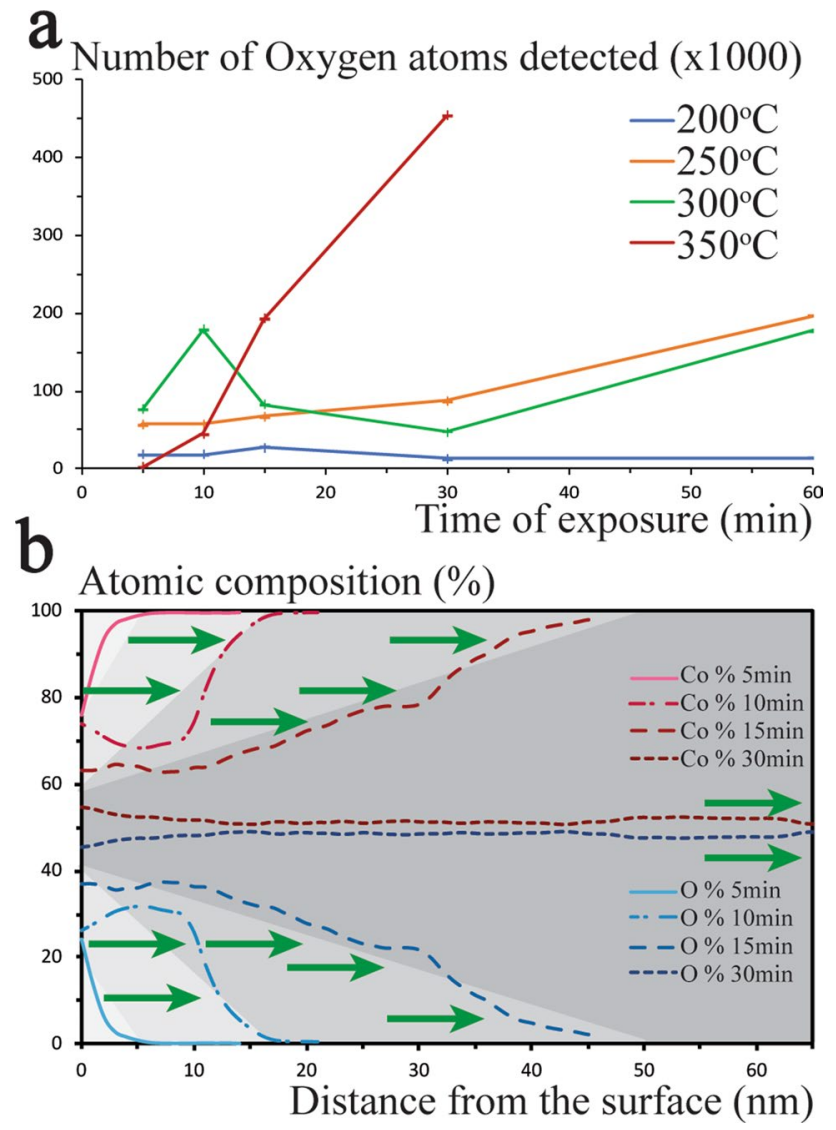

Fig. 4 Progression of oxidation on a single Co specimen over time. a Number of the oxygen atoms detected after successive oxygen treatments after 5, 10, 15, 30 and $60 \mathrm{~min}$ at 200, 250, 300 and $350{ }^{\circ} \mathrm{C}$. b Evolution of the penetrated oxygen front after 5, 10, 15 and $30 \mathrm{~min}$ at a constant temperature of $350{ }^{\circ} \mathrm{C}$

and $\mathrm{ZrO}_{2}$ layers (see Fig. 5a and b, with concentration profile across the oxide/metal interface given in 5c) [33]. In addition, the Sn distribution across the oxide/metal interface was investigated. After 5 min, a non-uniform distribution of $\mathrm{Sn}$ across the oxide metal interface and within the oxide was observed (see Fig. 5d, e, f). Sn was locally enriched in some regions of the oxide/metal interface (Fig. 5e), and depleted in others (Fig. 5f). Sn segregation in the oxide observed after 5 min at $300{ }^{\circ} \mathrm{C}$ may stabilise tetragonal $\mathrm{ZrO}_{2}$ grains $[60,61]$. While no $\mathrm{Sn}$ precipitates were observed within the oxide, the redistribution of Sn observed in the oxidation experiments may be indicative of precursors to the formation of larger Sn clusters, which may required more time at elevated temperature to develop [60]. Interestingly, the degree of $\mathrm{O}$ penetration into the base alloy was not consistent across the different oxide/metal interface facets. The presence of such directional $\mathrm{O}$ penetration requires further study on the structure across the oxide/metal interface via electron microscopy and/or FIM/FEM methods. It is also important to highlight that quantitative analysis of oxygen in oxide layers via APT is a significant challenge [62-64], and the oxide concentrations reported may be lower than true oxygen concentration. The use of isotopic tracers, such as ${ }^{18} \mathrm{O}$, as was performed in work by Bachhav et al. [63] may be helpful in improving accuracy of oxygen concentration measurements. Correlative high resolution transmission electron microscopy to identify structure of oxide phases is another experimental method that can help accurately assign oxide stoichiometries [33].

\subsection{Sample Preparation Considerations for In Situ APT Oxidation Studies}

It is crucial to consider the challenges behind the preparation of the various samples and the many steps involved in the experimental process for a successful application of this approach for the oxidation of metallic alloys. These processes and corresponding considerations are summarized in the flowchart shown in Fig. 6, and include: bulk sample preparation, APT needle preparation via the FIB lift-out method, transfer of specimens to the APT instrument, and movement of samples around the various chambers under UHV. An important note is that for such oxidation experiments, it is critical to understand, and ultimately reduce or eliminate, all instances when elements such as Gallium (Ga), $\mathrm{H}$ and $\mathrm{O}$ may be picked up by the sample or needle specimens at various points in the process from preparing bulk specimens to final polishing to transfer of specimens. Several considerations are listed in an effort to reduce $\mathrm{H}$ or $\mathrm{O}$ ingress from atmosphere, or the sample preparation environment. First, polishing procedures using non-aqueous media or ion milling can significantly reduce any $\mathrm{H}$ ingress during bulk sample preparation. For the data presented in Fig. 5, needles were prepared from a Zircaloy- 4 specimen that was ion milled. In addition, unintentional implantation of Gallium $(\mathrm{Ga})$ from the FIB-SEM during specimen preparation can damage the specimen surface, and possibly impact result from compositional analysis via APT. Ga segregation to the oxide/metal interface can affect interpretation of results related to composition at this interface. Ga contamination is most significant for the analysis of the oxide formed in air during sample transfer and is then removed during the field evaporation process in APT analysis. Initial analysis of the air oxide and removal of Ga contamination is thus an important first step for all subsequent high temperature oxidation studies using the reactor chamber. It is also noted that while Ga contamination is effectively reduced via the field evaporation process, it is not entirely removed, and could also impact subsequent analyses and should therefore be considered throughout the analysis process. The presence of high-Ga regions can reflect artificial trends in composition across the oxide/metal interface that do not represent any physical phenomena such as element partitioning or 

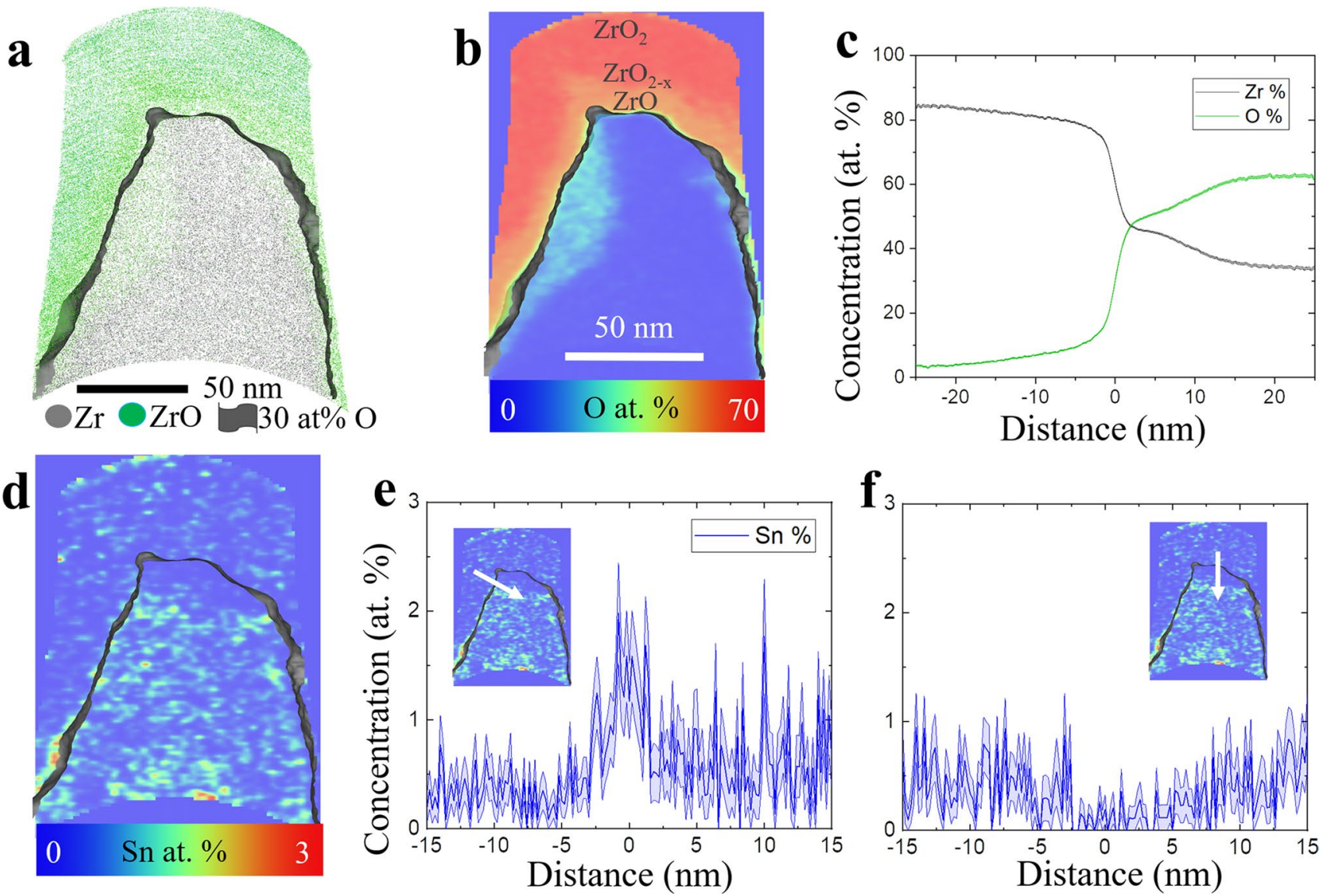

Fig. 5 Element distribution across the Zircaloy-4 alloy/oxide interface after oxidation at $300{ }^{\circ} \mathrm{C} \mathrm{O}_{2}$ gas at $10 \mathrm{mbar}$ for $5 \mathrm{~min}$. a A $10 \mathrm{~nm}$ thick "slice" of the 3D element distribution map for $\mathrm{Zr}$ and $\mathrm{ZrO}$ ions, with a 30 at $\% \mathrm{O}$ isoconcentration surface delineating the approximate alloy/oxide interface. 2D contour plot for b $\mathrm{O}$ concentration $(0-70$ at $\%$ ), and c proximity histogram for $\mathrm{Zr}$ and $\mathrm{O}$ across the 30 at $\% \mathrm{O}$ isoconcentration surface shown in (a) and (b). d 2D contour plot for

depletion. In an effort to reduce concerns associated with $\mathrm{Ga}$, alternative sample preparation methods should be considered, such as with the use of a Xe plasma FIB.

During FIB sample preparation sufficient material needs to be removed from the needle/Pt capping layer interface during final stages of annular milling using $2 \mathrm{kV}$ or $5 \mathrm{kV}$ with low current. The amount of material removed may vary based on bulk sample preparation methods, although it is noted that if a significant amount of material is removed $(\sim 1 \mu \mathrm{m})$, the needle shape becomes blunt, making atom probe analysis more challenging. The oxidation of $\mathrm{Zr}$ alloys (or other environmentallysensitive) materials is important to characterize by running all needles before oxidation. During this analysis, the air oxide formed in the transfer time from FIB to APT can be characterized. In the case of $\mathrm{Zr}$ alloys, $\mathrm{a} \sim 30$ at $\% \mathrm{O}$ oxide is formed [33]. Storage of specimens in vacuum should also be considered, but likely does not impact any $\mathrm{H}$ or O pick-up significantly. Pressure of all vacuum chambers should be monitored closely in
Sn (0-3 at\%) slice. e, f 1D concentration profiles within a cylinder positioned in the direction indicated by the white arrow in the figure insets, where e shows Sn enrichment, and $\mathbf{f}$ shows Sn depletion in different regions across the alloy/oxide interface. The error, based on counting statistics, is depicted by the light blue shaded bounding curve

order to ensure UHV is maintained during sample storage and during transfer between vacuum chambers. Lastly, residual $\mathrm{H}$ exists in the analysis chamber [65], and may adsorb onto the needle apex during analysis, making it difficult to distinguish between this residual $\mathrm{H}$ and solute $\mathrm{H}$. For these experiments, changes in $\mathrm{H}$ and $\mathrm{O}$ at $\%$ can be carefully tracked by analyzing the same needle before and after gas exposure. Best practices for minimizing $\mathrm{H}$ adsorption during atom probe analysis, and quantification challenges related to $\mathrm{Zr}$ alloys are detailed elsewhere [66-68]. 
$\underline{\text { Experimental Process }}$

Bulk sample preparation

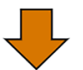

APT needle preparation (FIB lift-out)

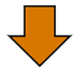

Transfer from FIB to APT load lock

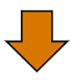

Move from load lock to buffer chamber

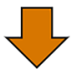

Storage in buffer chamber

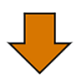

Move from buffer to analysis chamber and Data collection
Considerations

Polishing procedure (Metallographic preparation versus ion milling) can significantly impact sample surface from which FIB lift-outs are taken

- Analyzing below surface by removing top of APT needles during final polishing.

- Ga can damage the surface and change the reaction kinetics of Zirc4 with atmosphere

Distance between FIB lab and APT sample oxidation and/or H pick-up during sample transfer due to exposure to atmosphere

Typically overnight vacuum pumping from atmospheric pressure to low -8 torr pressure.

Any residual trace hydrogen or oxygen in buffer chamber could be picked-up by a reactive sample, such as $\mathrm{Zr}$-based alloys

Adsorbed $\mathrm{H}$ from the analysis chamber can be collected and may be difficult to separate from solute $\mathrm{H}$.

Fig. 6 Flowchart process for in situ APT oxidation studies and corresponding considerations

\section{Development of Operando APT Analysis for Metal Oxidation}

\subsection{Experimental Description Design and Operation}

FIM and FEM allows a real-time observation at the nanoscale of the model nanoparticle's surface but does not provide a direct chemical identification of the observation. APT allows this chemical identification with similar resolution but cannot provide a real time observation. With the use of a in situ reactor, each gas phase exposure for variable times corresponds to a "snapshot" of the complex dynamics. In the 1970s, Panitz started the development of the first Atom Probe also known as the "1-Dimensional Atom Probe" (1DAP) capable of probing the chemical composition of a small central area of the specimen [69]. In the 1980s Kruse, Abend and Block developed a new methodology using the 1DAP, also referring as "Pulsed Field Desorption Mass Spectrometry" (PFDMS), to provide directly kinetics measurements at the nanoscale [20]. This technique innovatively used the variable repetition rate of the E-field pulses, used to trigger field evaporation, to connect to a time of reaction $t_{R}$. As reactant gas adsorption takes place between pulses, each applied pulse desorbs adsorbates as ions which are projected towards the ion detector. By varying the frequency of voltage pulses, it becomes possible to study reaction dynamics such as observing the earlier stages of surface oxidation.
However, the 1DAP is only capable of probing a very small restricted area field of view of the surface [22]. In this section we present the first report of an adapted 1DAP application within a modern commercial APT system equipped with a position ion detector for studying surface reaction dynamics.

Our approach involves the use of the atom probe voltage pulses evaporation mode while exposing the sample to a very low pressure of $\mathrm{O}_{2}$ (up to $2.4 \times 10^{-9} \mathrm{mbar}$ ) in the analytical chamber. A gas introduction manifold on the FIM system has been modified on the LEAP APT system to allow evacuation of gases, including $\mathrm{O}_{2}$ from the gas manifold through the load lock to avoid any oxygen contamination in the buffer storage chamber (Fig. 7). To increase the rate of oxidation, the specimen stage cooling system is suspended and the specimen stage is heated to $300 \mathrm{~K}$. The sample surface is firstly cleaned by field evaporation at $300 \mathrm{~K}$ before oxygen gas is introduced in the analytical chamber. Considering the very low work pressure, we have chosen to perform our preliminary measurement on a material that is highly sensitive to the presence of oxygen: pure Co.

\subsection{Co Oxidation Observed in Real-Time with Operando APT}

A Co sample has been exposed to $2.36 \times 10^{-9}$ mbar of oxygen at $300 \mathrm{~K}$ within the LEAP APT system. The 3D 


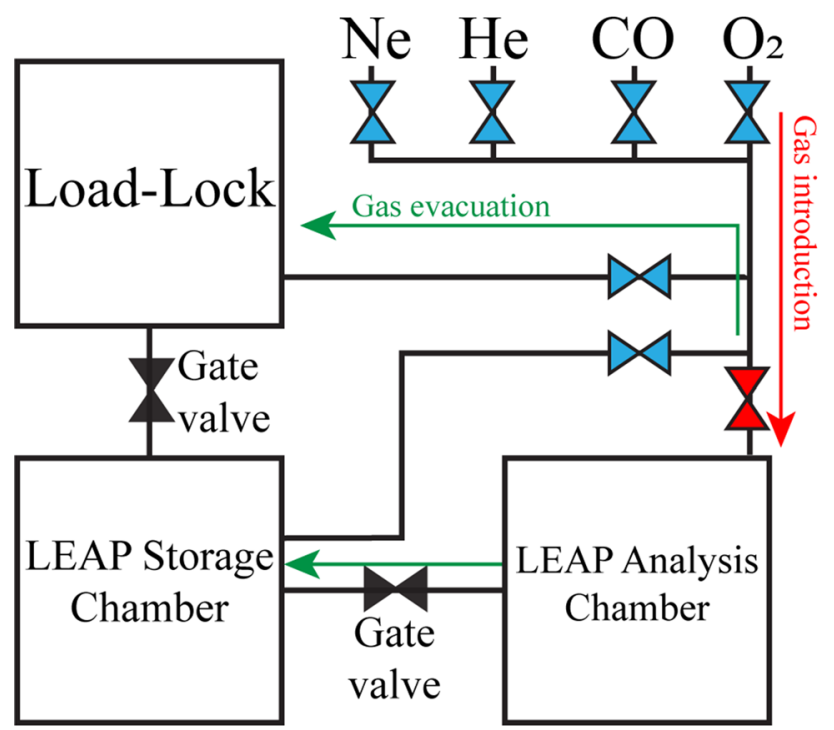

Fig. 7 Schematic description of the gas network connected to the LEAP analytical chamber for operando experiments

reconstructed APT results, shown in Fig. 9a, are of a "virtual" needle where the z-axis represents changes to the composition as a function of controlled reactant gas exposure in time. Under a constant applied bias, field evaporation occurs continuously, and the surface is constantly renewed.

The topmost part of the virtual needle corresponds to the beginning of the experiment with a pure Co surface shown as $\mathrm{z}=0$ in Fig. 8a. As soon that the oxygen is introduced in the chamber, the $\mathrm{Co}(\%)$ decreases while more $\mathrm{Co}_{\mathrm{x}} \mathrm{O}_{\mathrm{y}}$ $(x=1,2 ; y=0,1)$ are detected. The inertia of gas flow into the large size of the analysis chamber relative to the gas introduction manifold lines leads to a progressive increase of $\mathrm{P}\left(\mathrm{O}_{2}\right)$ during the experiment which was corrected manually (Fig. 8b). The comparison of the detected oxidation with the $\mathrm{P}\left(\mathrm{O}_{2}\right)$ plot shows a correlation between the slow $\mathrm{P}\left(\mathrm{O}_{2}\right)$ increasing and the increasing of $\mathrm{Co}_{\mathrm{x}} \mathrm{O}_{\mathrm{y}}$ detected. Different phases can be distinguished, with more or less $\mathrm{Co}^{\mathrm{n}+}, \mathrm{Co}_{2} \mathrm{O}^{\mathrm{n}+}$ or $\mathrm{CoO}^{\mathrm{n}+}(\mathrm{n}=1,2)$, but as soon as the $\mathrm{O}_{2}$ is evacuated from the analytical chamber, a clean Co surface is recovered. The detected $\mathrm{Co}_{2} \mathrm{O}^{\mathrm{n}+}$ and $\mathrm{CoO}^{\mathrm{n}+}$ variations corresponds to the variation of $\mathrm{P}\left(\mathrm{O}_{2}\right)$ and variation of voltage pulses frequency. The current LEAP system has a limited range of pulse frequencies available: 25,100 and $200 \mathrm{kHz}$, and a limited maximum voltage pulse of $1314 \mathrm{~V}$. Based on 1DAP principles, higher frequencies should reveal the earlier oxidation steps.

Additionally, the 2D projections of the different $\mathrm{Co}_{\mathrm{x}} \mathrm{O}_{\mathrm{y}}$ concentration reveal an inhomogeneous distribution of the different oxides along the surface. Most of the $\mathrm{CoO}^{\mathrm{n}+}$ are detected at the center while $\mathrm{Co}_{2} \mathrm{O}^{\mathrm{n}+}$ are detected at the periphery of the apex (Fig. 8c). The highest amount of $\mathrm{Co}_{2} \mathrm{O}$ detected can be identify as an early oxidation stage
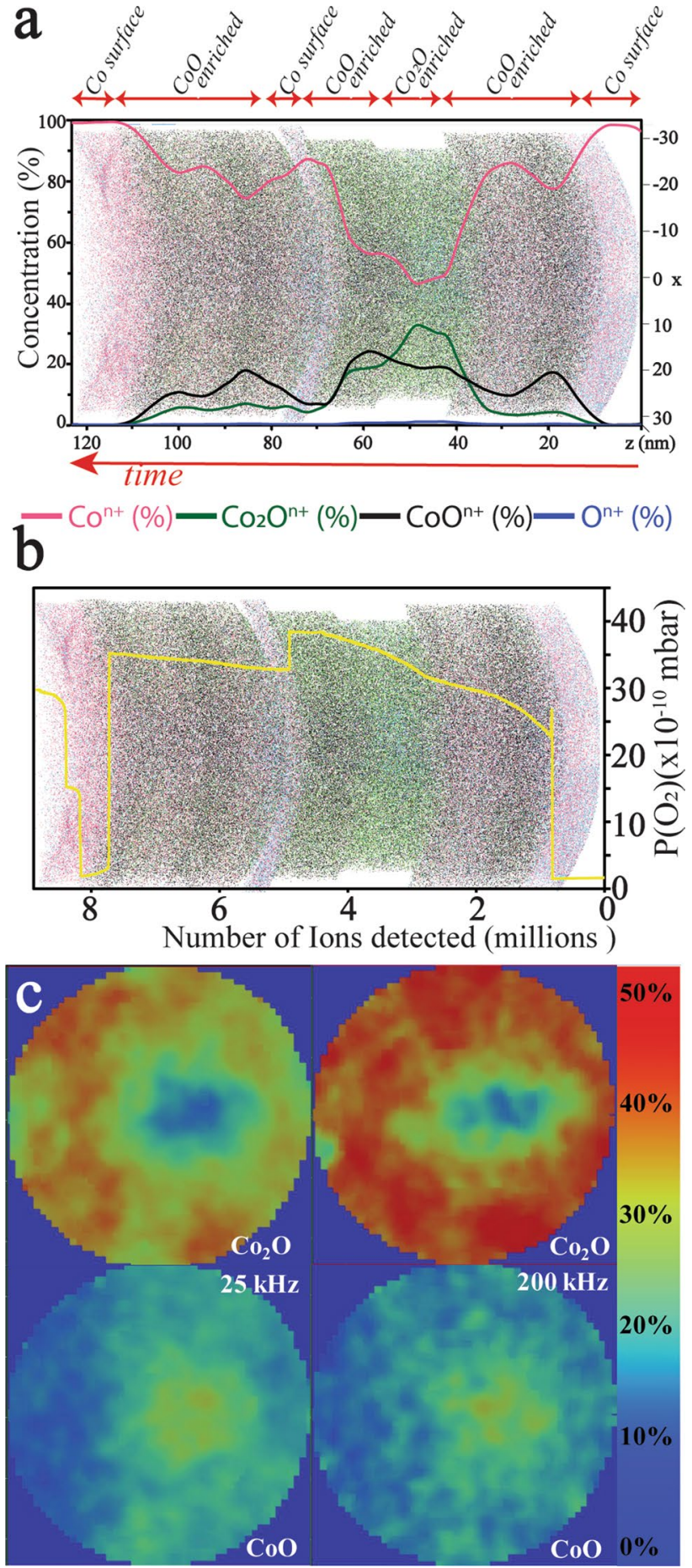

Fig. 8 a Graphic superposition of the virtual needle reconstruction with its 1D composition plot. Section can be distinguished with their enrichment in $\mathrm{Con}^{+}, \mathrm{Co}_{2} \mathrm{O}^{\mathrm{n}+}$ and $\mathrm{CoO}^{\mathrm{n}+}$, graphically distinguishable by their respective colors on the reconstruction: Pink, green and black respectively. b Graphic superposition of the virtual needle with the $\mathrm{P}\left(\mathrm{O}_{2}\right)$ plot. c 2D concentration projection of $\mathrm{Co}_{2} \mathrm{O}^{\mathrm{n}+}$ and $\mathrm{CoO}^{\mathrm{n}+}$ for section taken at 25 and $200 \mathrm{kHz}$ 


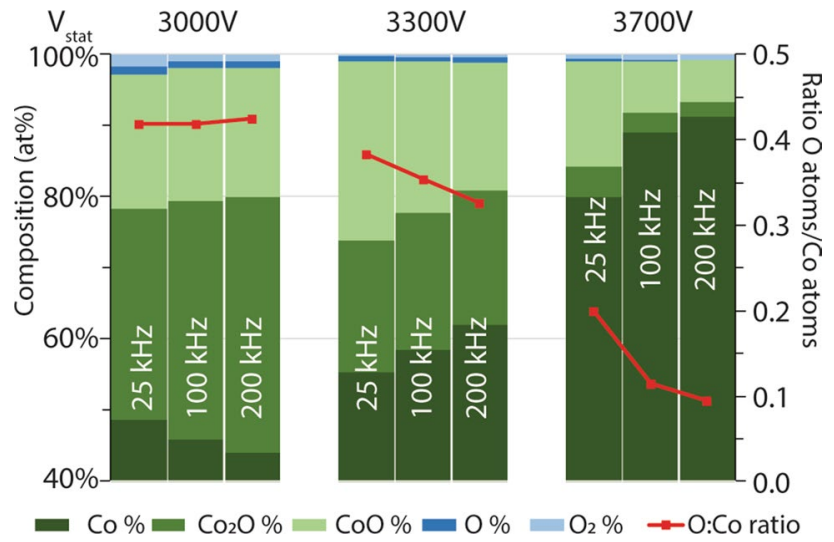

Fig. 9 Variations of the composition in $\mathrm{Co}^{\mathrm{n}+}, \mathrm{Co}_{2} \mathrm{O}^{\mathrm{n}+}, \mathrm{CoO}^{\mathrm{n}+}, \mathrm{O}^{\mathrm{n}+}$ and $\mathrm{O}_{2}^{\mathrm{n}+}$ species detected (at\% on the left scale and the O:Co ratio on the right scale) as a function of the static voltages $\left(\mathrm{V}_{\text {stat }}\right)$ and pulse frequencies applied

but the regular distribution of the $\mathrm{Co}_{2} \mathrm{O}^{\mathrm{n}+}$ make us to think that the surface oxidation may be influenced strongly by applied E-field during the oxidation process, thus providing a rational approach to further studying the effects of E-fields on surface reaction dynamics.

Within these preliminary experimental results, we were able to isolate three experimental sections in the whole measurement in which the $\mathrm{O}_{2}$ pressure and temperature were maintained constant at respectively $2.1 \times 10^{-9} \mathrm{mbar}$ and $300 \mathrm{~K}$, while maintaining a constant voltage at three different values of 3000,3300 and $3700 \mathrm{~V}$, and three constant pulsed frequencies of 25,100 , and $200 \mathrm{kHz}$. The difference between these sections lays in the applied stationary voltage of 3000,3300 and $3700 \mathrm{~V}$. For each of these conditions, we applied different voltage pulses frequencies $(25,100$ and $200 \mathrm{kHz}$ ) to observe its influence on the species detected. The composition of each section in different ions detected $\left(\mathrm{Co}^{\mathrm{n}+}, \mathrm{Co}_{2} \mathrm{O}^{\mathrm{n}+}, \mathrm{CoO}^{\mathrm{n}+}, \mathrm{O}^{\mathrm{n}+}\right.$ and $\left.\mathrm{O}_{2}^{\mathrm{n}+}\right)$ and the ratio of O:Co atoms are reported on Fig. 9. At $3000 \mathrm{~V}$ we can observe an almost constant $\mathrm{O}$ :Co ratio between the three different voltage pulses frequencies. The application of these different frequencies did not drastically impact the $\mathrm{CoO}^{\mathrm{n}+}(\%)$ detected. However, more noticeable differences are observed for $\mathrm{Co}^{\mathrm{n}+}(\%)$ and $\mathrm{Co}_{2} \mathrm{O}^{\mathrm{n}+}(\%)$ with respectively $48.6 \%{ }^{25 \mathrm{kHz}}$, $45.9 \%^{100 \mathrm{kHz}}, 44.0 \%^{200 \mathrm{kHz}}$ and $29.7 \%^{25 \mathrm{kHz}}, 33.4 \%^{100 \mathrm{kHz}}$, $36.0 \%{ }^{200 \mathrm{kHz}}$

The influence of the pulse frequency can be observed at higher voltage. At $3300 \mathrm{~V}$, both O:Co ratio and $\mathrm{CoO} \%$ increase as the frequency decreases and this difference is increasing even more markedly at $3700 \mathrm{~V}$. This preliminary observations at 3300 and $3700 \mathrm{~V}$ correlates with the Kruse et al. concept $[20,22]$ that at lower frequencies, the surface has more time to interact with $\mathrm{O}_{2}$ and form Co-oxides on the surface. The relative ratio of $\mathrm{Co}_{2} \mathrm{O}$ does not change as drastically as the ratio of detected $\mathrm{CoO}$, emphasizing the idea that
$\mathrm{Co}_{2} \mathrm{O}$ is a transient species as the system tends toward the formation of $\mathrm{CoO}$. However, the results at $3000 \mathrm{~V}$ suggest that the influence of the electric field must be considered in interpreting the results relevant to understanding the details of reaction kinetics.

The presence of a strong electric field, such as in the APT of several tens of V/nm, can drastically reshape the molecular orbitals of the $\mathrm{O}_{2}$ molecules as it has been described by Kreuzer et al. on $\mathrm{N}_{2}$ [70]. Consequently, $\mathrm{O}_{2}$ may become more reactive as its molecular bond is polarized in the presence of a strong inhomogeneous electric field near the surface and enhance its chemisorption rate. Additionally, the presence of a high electric field increases the rate of field evaporation of the surface leaving less time for $\mathrm{O}_{2}$ molecules to adsorb. Thus, the electric field plays a double role to enhance $\mathrm{O}_{2}$ reactivity while at the same time decreasing the rate of chemisorption through the constant field evaporation of the exposed surface. At $3000 \mathrm{~V}$, we can imagine that the presence of a relatively low electric field allows the surface to reach a higher O:Co ratio than at 3300 and $3700 \mathrm{~V}$. However, the precise reason for the higher relative portion of $\mathrm{Co}_{2} \mathrm{O} \%$ at high frequency is unknown where time-dependent computational methods may provide insight. Finally, we must consider that, despite a constant applied voltage, the electric field at the surface is varying as the specimen's radius of curvature increases over time as the surface is eroded by field evaporation. This supports the development in APT instrumentation that allows for the automatic adjusting of the applied voltage as a function of a constant detected O:Metal ratio (i.e. the maintaining of a constant evaporation electric field).

Despite the low working pressure used, it is possible to observe a surface oxidation phenomenon with the use of atom probe tomography. The use of a LEAP for operando experiments represents an advancement to developing a new type of experimental mode with APT. The next steps will explore the influence of the E-field by performing experiments without laser and only voltage pulses on different metals specimen surfaces to explore the temporal and spatial dynamics of metal oxide formation. A Rh single crystal will be used for the next attempts, where initial insight being provided via in situ reactor. These first experiments shown here reveal a promising new tool to explore, via a tridimensional map, the surface composition of a nanoparticle over time during an ongoing chemical reaction.

\section{Conclusion}

Recent developments in APM offer promise for investigating the complex composition and structure changes accompanying gas/surface interactions. The in situ reactor, for APT analysis first described by others [6, 36-39] and more 
broadly for APM analysis reported here and elsewhere [5], provides a new pathway for understanding atomic-scale processes involved in gas/surface reactions in a wide range of material systems, from single crystals of pure metals like $\mathrm{Rh}$, to more complex alloys such as zirconium alloys. We have detailed how APM allows the tracking of oxygen atoms from their adsorption on a Rh surface to their penetration within the bulk which is revealed to be highly sensitive to the different crystal structure composing the surface. Similarly, the systematic measurements at variable times allowed us to follow the progression of the oxygen penetration front inside of the Co bulk with the in situ reactor as well. In the case of Zircaloy-4, in situ reactor experiments revealed the formation of a multi-layered oxide film comprised of metastable phases and the important considerations on understanding influence of Ga implantation during sample preparation for such in situ reactor oxidation experiments is discussed. Finally, our first experiments of an "operando" mode of APT for Co oxidation demonstrates a promising application of Kruse et al.'s 1DAP Pulsed Field Desorption Mass Spectrometry methodology to a modern APT instrument and the necessity to pursue the develop of new instrumentation and methodologies.

The application of APM continues to progressively evolve, not only for materials mapping at the atomic scale, but also for the exploration of surface reactions. Correlative studies using real time observation with FIM and FEM, and in situ APT are capable of reconstructing the path of the adsorbents, from their formation on the surface, to their penetration and incorporation within the bulk. With this same approach in mind, correlative studies using other nanoscale to atomic scale imaging and chemical mapping techniques such as Environmental TEM (ETEM) [71], in situ SEM [72] and photoemission electron microscopy (PEEM) [16] must continue be considered. To establish a stronger understanding of the dynamic process of heterogeneous catalysis, the operando APT can allow for direct observation of nanoscale chemical reactions on surfaces in real time replacing the third spatial dimension by a time dimension.

\footnotetext{
Acknowledgements The work presented here was performed at Pacific Northwest National Laboratory (PNNL), which is operated for the U.S. DOE by Battelle Memorial Institute under Contract No. DE-AC0576RLO1830. A portion of this research was performed using facilities at the Environmental Molecular Sciences Laboratory, a national scientific user facility sponsored by the DOE Office of Biological and Environmental Research and located at PNNL. S.V.L. acknowledges the Linus Pauling Distinguished Postdoctoral Fellowship program at PNNL for financially supporting the Rh and Co studies. D.E.P. acknowledges support from the Laboratory Directed Research and Development (LDRD) program at PNNL. The Zircaloy-4 studies were supported by the open call Laboratory Directed Research and Development program at PNNL. The Zircaloy-4 materials were obtained from the U.S. Department of Energy (DOE) National Nuclear Security Administration under the tritium science programs. Initial development of the experimental approach for needle sample preparation in
}

FIB and transfer for studying oxidation of Zircaloy was also funded by the tritium science program. Authors are grateful for Prof. Norbert Kruse's and Hans Ruppender contribution to the construction of the in situ reactor and his pioneer involvement in the operando Atom Probe Microscopy developments dedicated to surface chemistry studies.

Author Contributions SVL performed the full Rh and Co specimen fabrication, experiments/data analysis, Zircaloy-4 oxidation experiments on APT and the paper redaction. EJK performed the Zircaloy-4 specimen fabrication, experiments/data analysis and paper redaction. MW and GJO contributed to the gas introduction network design and specimen fabrication ( $\mathrm{Rh}$ and $\mathrm{Co}$ ). $\mathrm{AD}$ contributed to the Zircaloy-4 data analysis and Zircaloy-4 section redaction. DEP contributed to the reactor/gas introduction network design and the paper redaction.

Funding The work presented here was performed using EMSL (grid.436923.9), a DOE Office of Science User Facility sponsored by the Office of Biological and Environmental Research and located at the Pacific Northwest National Laboratory (PNNL), which is operated for the U.S. DOE by Battelle Memorial Institute under Contract No. DE-AC05-76RLO1830. S.V.L. acknowledges the Linus Pauling Distinguished Postdoctoral Fellowship program at PNNL for financially supporting the Rh and Co studies. E.J.K., A.D. and D.E.P. acknowledges support from the Laboratory Directed Research and Development (LDRD) program at PNNL.

\section{Compliance with Ethical Standards}

Conflict of interest The authors have no competing interests to declare.

Open Access This article is licensed under a Creative Commons Attribution 4.0 International License, which permits use, sharing, adaptation, distribution and reproduction in any medium or format, as long as you give appropriate credit to the original author(s) and the source, provide a link to the Creative Commons licence, and indicate if changes were made. The images or other third party material in this article are included in the article's Creative Commons licence, unless indicated otherwise in a credit line to the material. If material is not included in the article's Creative Commons licence and your intended use is not permitted by statutory regulation or exceeds the permitted use, you will need to obtain permission directly from the copyright holder. To view a copy of this licence, visit http://creativecommons.org/licenses/by/4.0/.

\section{References}

1. Somorjai GA, Van Hove MA (1989) Adsorbate-induced restructuring of surfaces. Prog Surf Sci 30:201-231. https://doi. org/10.1016/0079-6816(89)90009-9

2. Somorjai GA, Li Y (2010) Introduction to surface chemistry and catalysis, 2nd edn. Wiley, Hoboken

3. Esposito D (2018) Mind the gap. Nature 1:807-808. https://doi. org/10.1038/s41929-018-0188-0

4. Rupprechter G, Weilach C (2007) Mind the gap! Spectroscopy of catalytically active phases. Nano Today 2:20-29. https://doi. org/10.1016/S1748-0132(07)70114-7

5. Lambeets SV, Visart de Bocarmé T, Perea DE, Kruse N (2020) Directional gateway to metal oxidation: 3D chemical mapping unfolds oxygen diffusional pathways in rhodium nanoparticles. J Phys Chem Lett 11:3144-3151. https://doi.org/10.1021/acs.jpcle tt.0c00321 
6. Dumpala S, Broderick SR, Bagot PAJ, Rajan K (2014) An integrated high temperature environmental cell for atom probe tomography studies of gas-surface reactions: instrumentation and results. Ultramicroscopy 141:16-21. https://doi.org/10.1016/j. ultramic.2014.03.002

7. McEwen JS, Rosa AGC, Gaspard P et al (2010) Non-equilibrium surface pattern formation during catalytic reactions with nanoscale resolution: investigations of the electric field influence. Catal Today 154:75-84. https://doi.org/10.1016/j.catto d.2010.02.070

8. Moors M, Visart de Bocarmé T, Kruse N (2009) $\mathrm{C}_{2} \mathrm{H}_{2}$ interaction with Ni nanocrystals: towards a better understanding of carbon nanotubes nucleation in CVD synthesis. Ultramicroscopy 109:381-384. https://doi.org/10.1016/j.ultramic.2008.09.003

9. Visart de Bocarmé T, Bär T, Kruse N (2001) In situ dynamic study of hydrogen oxidation on rhodium. Ultramicroscopy 89:75-82. https://doi.org/10.1016/S0304-3991(01)00114-0

10. Barroo C, De Decker Y, Jacobs L, Visart de Bocarmé T (2017) Nonlinear behavior during $\mathrm{NO}_{2}$ hydrogenation on a nanosized Pt-Rh catalyst sample. Appl Surf Sci 412:564-570. https://doi. org/10.1016/j.apsusc.2017.03.266

11. Bryl R, Olewicz T, Visart de Bocarmé T, Kruse N (2011) Thermal faceting of clean and oxygen-covered Ir nanocrystals. J Phys Chem C 115:2761-2768. https://doi.org/10.1021/jp109372v

12. Medvedev VK, Suchorski Y, Voss C et al (1998) Oxygen-induced reconstruction and surface oxidation of rhodium. Langmuir 14:6151-6157. https://doi.org/10.1021/la980603c

13. Rothfuss CJ, Medvedev VK, Stuve EM (2016) Cluster formation and distributions in field ionization of coadsorbed methanol and water on platinum. Surf Sci 650:130-139. https://doi. org/10.1016/j.susc.2015.12.023

14. Datler M, Bespalov I, Buhr S et al (2016) Hydrogen oxidation on stepped Rh surfaces: $\mu \mathrm{m}$-scale versus nanoscale. Catal Lett 146:1867-1874. https://doi.org/10.1007/s10562-016-1824-4

15. Owczarek S, Lambeets SV, Barroo C et al (2018) Oxygen assisted morphological changes of Pt nanosized crystals. Top Catal 61:1313-1322. https://doi.org/10.1007/s11244-018-0984-4

16. Suchorski Y, Bespalov I, Zeininger J et al (2020) CO oxidation on stepped Rh surfaces: $\mu \mathrm{m}$-scale versus nanoscale. Catal Lett 150:605-612. https://doi.org/10.1007/s10562-019-02950-0

17. Winkler P, Zeininger J, Raab M et al (2020) A novel wireless sample temperature control system for field ion, field electron, and atom probe techniques. Rev Sci Instrum 91:013705. https:// doi.org/10.1063/1.5126185

18. Gault B, Moody MP, Cairney JM, Ringer SP (2012) Atom probe microscopy. Springer, New York

19. Miller MK, Forbes RG (2014) Atom-probe tomography. Springer, Boston

20. Kruse N, Abend G, Block JH (1987) The kinetics of adsorption and thermal desorption of NO on stepped Pt single crystal surfaces. J Chem Phys 88:1307-1312. https://doi. org/10.1063/1.454201

21. Kruse N, Abend G, Block JH (1989) Formation of Rh-subcarbonyls during the reaction of $\mathrm{CO}, \mathrm{CO}_{2}$ and $\mathrm{CH}_{3} \mathrm{OH}$ with stepped $\mathrm{Rh}$ single crystal surfaces. Surf Sci 211(212):1038-1043. https://doi. org/10.1016/0039-6028(89)90872-8

22. Kruse N (2000) Nitric oxide interaction with Rh metal: kinetics of elemental steps and reaction with carbon monoxide. $\mathrm{J}$ Mol Catal A: Chem 163:79-89. https://doi.org/10.1016/S1381 $-1169(00) 00401-5$

23. Rothfuss CJ, Medvedev VK, Stuve EM (2002) Temperature and field dependence of protonated water cluster emission from field adsorbed water layers on platinum. Surf Sci 501:169-181. https ://doi.org/10.1016/S0039-6028(01)01942-2

24. Rothfuss CJ, Medvedev VK, Stuve EM (2003) The influence of the surface electric field on water ionization: a two step dissociative ionization and desorption mechanism for water ion cluster emission from a platinum field emitter tip. J Electroanal Chem 554 555:133-143. https://doi.org/10.1016/S0022-0728(03)00131-1

25. Gurlo A, Riedel R (2007) In situ and operando spectroscopy for assessing mechanisms of gas sensing. Angew Chemie Int Ed 46:3826-3848. https://doi.org/10.1002/anie.200602597

26. Visart de Bocarmé T, Chau TD, Kruse N (2006) Imaging and probing catalytic surface reactions on the nanoscale: field ion microscopy and atom-probe studies of $\mathrm{O}_{2}-\mathrm{H}_{2} / \mathrm{Rh}$ and NO$-\mathrm{H}_{2} /$ Pt. Top Catal 39:111-120. https://doi.org/10.1007/s1124 4-006-0044-3

27. Barroo C, Lambeets SV, Devred F et al (2014) Hydrogenation of $\mathrm{NO}$ and $\mathrm{NO}_{2}$ over palladium and platinum nanocrystallites: case studies using field emission techniques. New J Chem 38:2090 2097. https://doi.org/10.1039/c3nj01505j

28. Barroo C, De Decker Y, Visart de Bocarmé T, Kruse N (2016) Emergence of chemical oscillations from nanosized target patterns. Phys Rev Lett 117:144501. https://doi.org/10.1103/PhysR evLett.117.144501

29. Lambeets SV, Barroo C, Owczarek S et al (2017) Adsorption and hydrogenation of $\mathrm{CO}_{2}$ on Rh nanosized crystals demonstration of the role of inter-facet oxygen spillover and comparative studies with $\mathrm{O}_{2}, \mathrm{~N}_{2} \mathrm{O}$ and CO. J Phys Chem C 121:16238-16429. https:// doi.org/10.1021/acs.jpcc.7b02217

30. Kruse N (1990) Timeresolved reaction studies on the atomic scale: $\mathrm{NO}$ and $\mathrm{CO}$ adsorption on stepped Rh surfaces time-resolved reaction studies on the atomic scale: $\mathrm{NO}$ and $\mathrm{CO}$ adsorption on stepped Rh surfaces. J Vac Sci Technol, A 8:3432-3436. https:// doi.org/10.1116/1.576527

31. Che F, Gray JT, Ha S et al (2018) Elucidating the roles of electric fields in catalysis: a perspective. ACS Catal 8:5153-5174. https ://doi.org/10.1021/acscatal.7b02899

32. Müller E, Tsong TT (1969) Field ion microscopy principles and applications, 1st edn. Elsevier Publishing Company Inc, New York

33. Kautz EJ, Gwalani B, Lambeets SV et al (2020) Rapid assessment of structural and compositional changes during early stages of zirconium alloy oxidation. npj Mater Degrad. https://doi. org/10.1038/s41529-020-00133-6

34. Thompson K, Lawrence D, Larson DJ et al (2007) In situ sitespecific specimen preparation for atom probe tomography. Ultramicroscopy 107:131-139

35. Devaraj A, Perea DE, Liu J et al (2017) Three-dimensional nanoscale characterisation of materials by atom probe tomography. Int Mater Rev 63:68-101. https://doi.org/10.1080/09506 608.2016.1270728

36. Haley D, McCarroll I, Bagot PAJ et al (2019) A gas-phase reaction cell for modern atom probe systems. Microsc Microanal 25:410-417. https://doi.org/10.1017/S1431927618016240

37. McCarroll IE, Haley D, Thomas S et al (2020) The effect of hydrogen on the early stages of oxidation of a magnesium alloy. Corros Sci 165:108391. https://doi.org/10.1016/j.corsci.2019.108391

38. Bagot PAJ, Visart de Bocarmé T, Cerezo A, Smith GDW (2006) 3D atom probe study of gas adsorption and reaction on alloy catalyst surfaces I: instrumentation. Surf Sci 600:3028-3035. https:// doi.org/10.1016/j.susc.2006.05.026

39. Gilis N, Jacobs L, Barroo C, Visart de Bocarmé T (2018) Surface segregation in $\mathrm{Au}-\mathrm{Ag}$ alloys investigated by atom probe tomography. Top Catal 61:1437-1448. https://doi.org/10.1007/s1124 4-018-1040-0

40. Perea DE, Gerstl SSA, Chin J et al (2017) An environmental transfer hub for multimodal atom probe tomography. Adv Struct Chem Imaging 3:12. https://doi.org/10.1186/s40679-017-0045-2

41. Ganduglia-Pirovano MV, Reuter K, Scheffler M (2002) Stability of subsurface oxygen at Rh(111). Phys Rev B 65:2454261-2454269. https://doi.org/10.1103/PhysRevB.65.245426 
42. Farber RG, Turano ME, Killelea DR (2018) Identification of surface sites for low-temperature heterogeneously catalyzed CO oxidation on Rh(111). ACS Catal 8:11483-11490. https://doi. org/10.1021/acscatal.8b03887

43. Rytter E, Holmen A (2015) Deactivation and regeneration of commercial type fischer-tropsch co-catalysts-a mini-review. Catalysts 5:478-499. https://doi.org/10.3390/catal5020478

44. Zhang Q, Kang J, Wang Y (2010) Development of novel catalysts for Fischer-Tropsch synthesis: tuning the product selectivity. ChemCatChem 2:1030-1058. https://doi.org/10.1002/cctc.20100 0071

45. Wang L, Guan E, Wang Y et al (2020) Silica accelerates the selective hydrogenation of $\mathrm{CO}_{2}$ to methanol on cobalt catalysts. Nat Commun 11:1-9. https://doi.org/10.1038/s41467-020-14817-9

46. Iablokov V, Barbosa R, Pollefeyt $\mathrm{G}$ et al (2015) Catalytic CO oxidation over well-defined cobalt oxide nanoparticles: size-reactivity correlation. ACS Catal 5:5714-5718. https://doi.org/10.1021/ acscatal.5b01452

47. Xiang Y, Kovarik L, Kruse N (2019) Rate and selectivity hysteresis during the carbon monoxide hydrogenation over promoted $\mathrm{Co} /$ MnOx catalysts. Nat Commun 10:3953. https://doi.org/10.1038/ s41467-019-11836-Z

48. Athariboroujeny M, Raub A, Iablokov V et al (2019) Competing mechanisms in $\mathrm{CO}$ hydrogenation over $\mathrm{Co}-\mathrm{MnOx}$ catalysts. ACS Catal 9:5603-5612. https://doi.org/10.1021/acscatal.9b00967

49. Xiang Y, Chitry V, Liddicoat P et al (2013) Long-chain terminal alcohols through catalytic $\mathrm{CO}$ hydrogenation. J Am Chem Soc 135:7114-7117. https://doi.org/10.1021/ja402512r

50. Nishikawa O, Müller EW (1967) Field-ion microscopy of cobalt. J Appl Phys 38:3159-3167. https://doi.org/10.1063/1.1710081

51. Su J, Zhang Z, Fu D et al (2016) Higher alcohols synthesis from syngas over $\mathrm{CoCu} / \mathrm{SiO}_{2}$ catalysts: dynamic structure and the role of $\mathrm{Cu}$. J Catal 336:94-106. https://doi.org/10.1016/j. jcat.2016.01.015

52. Vurpillot F, Parviainen S, Djurabekova F et al (2018) Simulation tools for atom probe tomography: a path for diagnosis and treatment of image degradation. Mater Charact 146:336-346. https:// doi.org/10.1016/j.matchar.2018.04.024

53. Santhanagopalan D, Schreiber DK, Perea DE et al (2015) Effects of laser energy and wavelength on the analysis of $\mathrm{LiFePO}_{4}$ using laser assisted atom probe tomography. Ultramicroscopy 148:5766. https://doi.org/10.1016/j.ultramic.2014.09.004

54. Bagot PAJ, Kruska K, Haley D et al (2014) Oxidation and surface segregation behavior of a Pt-Pd-Rh. Alloy Catal. https://doi. org/10.1021/jp508144z

55. Burns KA, Love EF, Thornhill CK (2012) Description of the tritium- producing burnable absorber rod for the commercial light water reactor. PNNL, Richland

56. Cahn RW, Haasen P, Kramer EJ, et al (1994) Zirconium alloys in nuclear applications. In: Materials science and technology A comprehensive treatment. VCH Verlagsgesellschaft $\mathrm{mbH}$, Weiheim, $\mathrm{p}$ 1401

57. Rickover HG, Geiger LD, Lustman B (1975) History of the development of zirconium alloys for use in nuclear reactors. Energy Research and Development Administration, Washington, DC

58. Motta AT, Couet A, Comstock RJ (2015) Corrosion of zirconium alloys used for nuclear fuel cladding. Annu Rev Mater
Res 45:311-343. https://doi.org/10.1146/annurev-matsci-07021 4-020951

59. Ni N, Hudson D, Wei J et al (2012) How the crystallography and nanoscale chemistry of the metal/oxide interface develops during the aqueous oxidation of zirconium cladding alloys. Acta Mater 60:7132-7149. https://doi.org/10.1016/j.actamat.2012.09.021

60. Sundell G, Thuvander M, Andrén H-O (2015) Tin clustering and precipitation in the oxide during autoclave corrosion of Zircaloy-2. J Nucl Mater 456:409-414. https://doi.org/10.1016/j. jnucmat.2014.10.003

61. Wei J, Frankel P, Polatidis E et al (2013) The effect of Sn on autoclave corrosion performance and corrosion mechanisms in $\mathrm{Zr}-\mathrm{Sn}$ $\mathrm{Nb}$ alloys. Acta Mater 61:4200-4214. https://doi.org/10.1016/j. actamat.2013.03.046

62. Gault B, Saxey DW, Ashton MW et al (2016) Behavior of molecules and molecular ions near a field emitter. New J Phys 18:033031. https://doi.org/10.1088/1367-2630/18/3/033031

63. Bachhav M, Danoix F, Hannoyer B et al (2013) Investigation of O-18 enriched hematite $\left(\alpha-\mathrm{Fe}_{2} \mathrm{O}_{3}\right)$ by laser assisted atom probe tomography. Int J Mass Spectrom 335:57-60. https://doi. org/10.1016/j.ijms.2012.10.012

64. Devaraj A, Colby R, Hess WP et al (2013) Role of photoexcitation and field ionization in the measurement of accurate oxide stoichiometry by laser-assisted atom probe tomography. J Phys Chem Lett 4:993-998. https://doi.org/10.1021/jz400015h

65. Redhead PA (2003) Hydrogen in vacuum systems: an overview. AIP Conf Proc 671:243-254. https://doi.org/10.1063/1.1597372

66. Mouton I, Breen AJ, Wang S et al (2019) Quantification challenges for atom probe tomography of hydrogen and deuterium in Zircaloy-4. Microsc Microanal 25:481-488. https://doi. org/10.1017/S143192761801615X

67. Sundell G, Thuvander M, Andrén H-O (2013) Hydrogen analysis in APT: methods to control adsorption and dissociation of $\mathrm{H} 2$. Ultramicroscopy 132:285-289. https://doi.org/10.1016/j.ultra mic.2013.01.007

68. Kolli RP (2017) Controlling residual hydrogen gas in mass spectra during pulsed laser atom probe tomography. Adv Struct Chem Imaging 3:10. https://doi.org/10.1186/s40679-017-0043-4

69. Panitz JA (1973) The $10 \mathrm{~cm}$ atom probe. Rev Sci Instrum 44:1034-1038

70. Karahka ML, Kreuzer HJ (2016) New physics and chemistry in high electrostatic fields. Surf Sci 643:164-171. https://doi. org/10.1016/j.susc.2015.08.014

71. Wang Y, Li M, Yang Y et al (2020) In-situ surface transformation of magnesium to protect against oxidation at elevated temperatures. J Mater Sci Technol 44:48-53. https://doi.org/10.1016/j. jmst.2019.10.018

72. Barroo C, Wang Z, Schlögl R, Willinger M (2020) Imaging the dynamics of catalysed surface reactions by in situ scanning electron microscopy. Nat Catal 3:1-10. https://doi.org/10.1038/s4192 9-019-0395-3

Publisher's Note Springer Nature remains neutral with regard to jurisdictional claims in published maps and institutional affiliations. 